\title{
Canonical Notch Signaling Is Not Necessary for Prosensory Induction in the Mouse Cochlea: Insights from a Conditional Mutant of $R B P j \kappa$
}

\author{
Martín L. Basch, ${ }^{1}$ Takahiro Ohyama, ${ }^{3}$ Neil Segil, ${ }^{3,4}$ and Andrew K. Groves ${ }^{1,2}$ \\ ${ }^{1}$ Departments of Neuroscience and Molecular and Human Genetics, and ${ }^{2}$ Program in Developmental Biology, Baylor College of Medicine, Houston, Texas \\ 77030, ${ }^{3}$ Division of Cell Biology and Genetics, House Ear Institute, Los Angeles, California 90057, and ${ }^{4}$ Department of Cell and Neurobiology, Keck School of \\ Medicine, University of Southern California, Los Angeles, California 90033
}

\begin{abstract}
The mammalian organ of Corti consists of a highly organized array of hair cells and supporting cells that originate from a common population of prosensory progenitors. Proper differentiation of this complex cellular mosaic requires lateral inhibition mediated by Notch signaling. Several studies have implicated Notch signaling in the earlier induction of the prosensory domain that lies along the length of the cochlear duct, and which forms before the onset of hair cell and supporting cell differentiation. To investigate the role of Notch signaling in prosensory domain formation, we conditionally inactivated the transcriptional mediator of canonical Notch signaling, $R В P j \kappa$, throughout the inner ear. Although $R В P j \kappa$ mutants have severe vestibular defects and a shortened cochlear duct, markers of the prosensory domain appear at the normal time and location in the cochlea of RBPj $\kappa$ mutants. Despite the lack of $R B P j \kappa$, hair cell and supporting cell markers also appear at appropriate times in the cochlea, suggesting that $R B P j \kappa$ is dispensable for differentiation of the cochlear sensory epithelium. However, we also observed that differentiating hair cells and supporting cells rapidly die in $R B P j \kappa$ mutants, suggesting a requirement of $R В P j \kappa$ for cell survival in this tissue. Finally, in contrast to the chick basilar papilla, ectopic activation of Notch signaling did not induce ectopic sensory patches in nonsensory regions of the cochlea. Our results indicate that canonical Notch signaling is not necessary for prosensory specification in the mouse cochlea, suggesting that other signaling pathways may specify this highly derived sensory organ.
\end{abstract}

\section{Introduction}

The organ of Corti is a highly patterned cellular mosaic, with one row of inner hair cells and three rows of outer hair cells surrounded by several different types of supporting cells. The organ of Corti arises from a common population of postmitotic cells in the cochlea, termed the prosensory domain (Chen et al., 2002; Kelley, 2006). It is not clear how this region of the cochlea becomes specified, but analogies with the development of the eye and peripheral nervous system in Drosophila have led to the idea that the Notch signaling pathway may be necessary for the formation of inner ear prosensory domains (Eddison et al., 2000;

\footnotetext{
Received Dec. 21, 2010; revised March 28, 2011; accepted April 17, 2011.

Author contributions: M.L.B., T.O., N.S., and A.K.G. designed research; M.L.B., T.O., and A.K.G. performed research; M.L.B. and A.K.G. analyzed data; M.L.B., N.S., and A.K.G. wrote the paper.

This work was supported by the House Ear Institute and by the National Institutes of Health Grants DC006185 (to A.K.G. and N.S.), DC004189 (to N.S.), and DC004675 (to A.K.G.). We thank Tasuku Honjo for the gift of RBPJא conditional mice; Raphael Kopan for providing breeding pairs; Pamela Stanley for Pofut1 conditional mice; Julian Lewis for Jag 1 conditional mice; Jeffrey Nye, Urban Lendahl, and Manfred Gessler for cDNA probes; and Juan Llamas, Welly Makmura, Francesca Della Ripa, and Hongyuan Zhang for excellent technical assistance with genotyping and mouse husbandry. We also thank Amy Kiernan, Angelika Doetzlhofer, Shinya Yamamoto, Wu-Lin Charng, and Mardelle Atkins for helpful discussions, Joana Neves for an important experimental suggestion; and Norio Yamamoto and Matt Kelley for discussing our data prior to publication.

Correspondence should be addressed to either of the following: Andrew Groves, Baylor College of Medicine, BCM295, 1 Baylor Plaza, Houston, TX 77030, E-mail: akgroves@bcm.edu, or Neil Segil, House Ear Institute, 2100 West 3rd Street, Los Angeles, CA 90057, E-mail: nsegil@hei.org.

DOI:10.1523/JNEUROSCI.6671-10.2011

Copyright $\odot 2011$ the authors $\quad 0270-6474 / 11 / 318046-13 \$ 15.00 / 0$
}

Daudet and Lewis, 2005). In this scheme, Notch signaling is postulated to act twice during the generation of sensory cells, with an initial phase of Notch signaling inducing prosensory patches and a second phase establishing the fine-grained pattern of hair cells and supporting cells through lateral inhibition (Daudet and Lewis, 2005).

Several lines of evidence support this two-phase model of Notch action in the mammalian cochlea. First, components of the Notch pathway are expressed in a location consistent with a role in prosensory specification (Lanford et al., 1999; Morrison et al., 1999; Zine et al., 2000; Zine and de Ribaupierre, 2002; Hayashi et al., 2008). Second, activation of Notch1 at early stages of ear development can induce ectopic sensory patches containing both hair cells and supporting cells near the chicken vestibular organs and basilar papilla (Daudet and Lewis, 2005) and in nonsensory regions of the mouse cochlea (Hartman et al., 2010; Pan et al., 2010). Third, Jag1 conditional mutant mice show a downregulation of prosensory markers and have severely reduced numbers of hair cells and supporting cells in the organ of Corti (Brooker et al., 2006; Kiernan et al., 2006). However, other loss-of-function experiments using the gamma-secretase inhibitor DAPT to prevent Notch signaling gave conflicting results on the formation of the prosensory domain and differentiation of the organ of Corti (Takebayashi et al., 2007; Hayashi et al., 2008). Moreover, Notch1 conditional mutants or compound Jag2/Delta1 mutants show no defects in prosensory formation and only exhibit supernumerary 
hair cells predicted by a failure of Notch-mediated lateral inhibition in the organ of Corti (Kiernan et al., 2005a).

In light of these data, it is still unclear whether Notch signaling is required for the initial induction of a prosensory domain in cochlear development before the requirement for Notch-dependent lateral inhibition during hair cell and supporting cell differentiation. The canonical Notch signaling pathway involves binding of Delta or Jagged ligands of Notch receptors, resulting in the cleavage and release of the intracellular domain of the Notch receptor (NICD). NICD travels to the nucleus and forms a transcriptional complex with $\mathrm{RBPj} \kappa$, the transcriptional mediator of the canonical pathway (Honjo, 1996; Tanigaki and Honjo, 2010). To address the role of canonical Notch signaling in induction of the cochlear prosensory domain, we conditionally inactivated $R B P j \kappa$ in the entire inner ear. Our data suggest that canonical Notch signaling is neither necessary nor sufficient for the induction of the prosensory domain in the developing mammalian cochlea.

\section{Materials and Methods}

Conditional inactivation of RBPj $\kappa$, Jag1, and Pofut 1 in the inner ear. Mice homozygous for conditional alleles of RBPjк (Han et al., 2002), Jag1 (Brooker et al., 2006), or Pofut1 (Shi et al., 2005) were crossed with Pax2-Cre mice (Ohyama and Groves, 2004) that were also heterozygous for a null mutation in the gene of interest. Pax2-Cre mice are available from the Mutant Mouse Reginal Resource Centers (stock number 010569UNC). The ROSA-EYFP Cre reporter line (Srinivas et al., 2001) is available from Jackson Laboratories (stock number 006148). The following primers were used for genotyping: Pax2-Cre: CrelF (GCCTGCATTACCGGTCGATGCAACGA) and Cre1R (GTGGCAGATGGCGCGGCAACACCATT) yield a 700 bp band; $R B P j \kappa$ floxed, deleted, and wild-type allele: RBPJ1 (AACATCCACAGCAGGCAA), RBPJ2 (GATAGACCTTGGTTTGTTTGG), and RBPJ3 (CCACTGTTGTGAACTGGCGTGG) yield a $500 \mathrm{bp}$ floxed allele band, a $700 \mathrm{bp}$ deleted allele band, and a $300 \mathrm{bp}$ wild-type allele band, respectively; Jag1 floxed, deleted, and wild-type allele: J1C, (TGA ACT CAG GAC AGT GCT C), J1D (ATA GGA GGC CAT GGA TGA CT), and J1F (GTT TCA GTG TCT GCC ATT GC) yield a 500 bp floxed allele band, a 330 bp deleted allele band, and a 390 bp wild-type allele band, respectively; and Pofut1 foxed, deleted, and wild-type allele: PS644 (GGG TCA CCT TCA TGT ACA AGT GAG TG) and PS645 (ACC CACAGG CTG TGC AGT CTT TG) yield a $960 \mathrm{bp}$ floxed allele band and either a $700 \mathrm{bp}$ wild-type band or a 300 bp deleted allele band, respectively.

Inducible activation of N1ICD. Mice carrying a conditionally activated Notch1 intracellular domain followed by an IRES-GFP sequence (cN1ICD ${ }^{\text {floxed/floxed }}$ ) (Murtaugh et al., 2003) were crossed to B6.Cg-Tg (CAG-cre/Esr1) $^{5 \mathrm{Amc/I}}$ mice (Jax stock number 004682) (Hayashi and McMahon, 2002) in which the Cre gene is fused to a tamoxifen-sensitive mutant of the estrogen receptor. The resulting cN1ICD;CMV-Cre/ESR1 offspring express Notch1-ICD and GFP after exposure to tamoxifen.

Organotypic cochlear culture and electroporation. Cochleas from E13.5 mice were collected in PBS and incubated in calcium-magnesium-free PBS containing dispase $(1 \mathrm{mg} / \mathrm{ml}$; Invitrogen $)$ and collagenase $(1 \mathrm{mg} / \mathrm{ml}$; Worthington) for $8 \mathrm{~min}$ at room temperature as previously described (Doetzlhofer et al., 2009) to free the cochlear duct from surrounding condensed mesenchyme tissue. Embryonic cochlear explants were cultured on SPI black membranes (SPI Supplies) in DMEM-F12 (Invitrogen) with $\mathrm{N} 2$ supplement (Invitrogen). All cultures were maintained in a $5 \% \mathrm{CO}_{2} / 20 \% \mathrm{O}_{2}$ humidified incubator. For induction of N1ICD-IRESGFP, a $5 \mathrm{~mm}$ solution of OH-tamoxifen (Sigma-Aldrich) in 95\% ethanol was added to the medium for a final concentration of $5 \mu \mathrm{M}$. Cochlea electroporations were performed as previously described (Doetzlhofer et al., 2009).

Paint filling of the inner ear. Paint fillings of E13.5 inner ears from either CD1 mice or RBPjк conditional mutants were performed based on a protocol from Kiernan et al. (2006). Injections of $0.1 \%$ gloss white paint in methyl salicylate were done by hand using a Picospritzer III pressure injector (General Valve Corporation).
In situ hybridization. The inner ears from E14.5, E16.5, or P1 mice were fixed in $4 \%$ paraformaldehyde in PBS overnight at $4^{\circ} \mathrm{C}$, sunk in $30 \%$ sucrose in PBS at $4^{\circ} \mathrm{C}$, incubated in OCT at room temperature for $1 \mathrm{~h}$, and frozen in liquid nitrogen. Digoxigenin-labeled antisense ribroprobes to mouse Notch1, Notch3, Hey2, and Bmp4 were synthesized using standard protocols (Stern, 1998). The in situ hybridization procedure was modified from a protocol by Henrique et al. (1995). Detailed protocols are available upon request.

Immunohistochemistry. Antibodies used in this study were antiactivated caspase-3 (Cell Signaling Technology), anti-p27 Kip1 (NeoMarker), anti-parvalbumin and clone PARV-19 (Sigma), anti-myosin-VI (Proteus), anti-Jagged1 (Santa Cruz Biotechnology), anti-Proxl (Millipore Bioscience Research Reagents), anti-Hey2 (Doetzlhofer et al., 2009), anti-RBPJ $\kappa$ (CosmoBio), and anti-Notch1 intracellular domain (Millipore). Fluorescently labeled secondary antibodies were Alexa-594 or Alexa-488 from Invitrogen. Secondary anti-rabbit HRP conjugated from Invitrogen. DAB staining was done using a DAB kit (Vector Labs). For anti-p27 ${ }^{\text {Kip } 1}$ staining and Jagged 1 , sections were boiled for $10 \mathrm{~min}$ in $10 \mathrm{~mm}$ citric acid, pH 6.0. RBPJk and NICD stainings were performed as previously described (Morimoto et al., 2010).

Quantitative real-time PCR. For RNA extraction, total RNA from dissected cochleas or cultured cochlear explants was isolated by using a Qiagen RNeasy Micro kit. cDNA was synthesized by using Superscript III First Strand Synthesis System for RT-PCR (Invitrogen). Quantitative realtime PCR (qPCR) was performed with a Master SYBR Green kit (Applied Biosystems) and gene-specific primer sets on a Step One Plus real-time PCR system (Applied Biosystems). Each PCR was performed in triplicate. Relative gene expression was analyzed by using the DDCT method (Livak and Schmittgen, 2001) and L19 was used as an endogenous reference. The genespecific primer sets used were as follows: L19 (RpL19): $5^{\prime}$-ggtctggttggatcccaatg- $3^{\prime}$ and $5^{\prime}$-cccgggaatggacagtca- $3^{\prime}$, Hes1: $5^{\prime}$-gcttcagcgagtgcatgaac- $3^{\prime}$ and $5^{\prime}$-cggtgttaacgccctcaca- $3^{\prime}$, Hes5: $5^{\prime}$-gcaccagcccaactccaa-3 and $5^{\prime}$ ggcgaaggctttgctgtgt- $3^{\prime}$, Heyl: 5' -cactgcaggagggaaaggttat- $3^{\prime}$ and $5^{\prime}$-ccccaaactccgatagtccat- $3^{\prime}$, Hey2: $5^{\prime}$-aagcgcccttgtgaggaaa- $3^{\prime}$ and $5^{\prime}$-tcgctccccacgtcgat- $3^{\prime}$, HeyL: 5'-gcgcagagggatcatagagaa- $3^{\prime}$ and $5^{\prime}$-tcgcaattcagaaaggctactg- $3^{\prime}$, RBPJ $\kappa: 5^{\prime}$-tggctacatccattacgggcag- $3^{\prime}$ and $5^{\prime}$-gtggagttgtgatacagggtcg $3^{\prime}$.

TUNEL cell death assay. For cell death detection using the TUNEL method, we used a TMR in situ cell detection kit (Roche) with a modified protocol based on manufacturer's instructions (protocol is available upon request).

\section{Results}

\section{Timeline of prosensory development and Notch pathway activation in the cochlea}

The mouse cochlea develops as an outgrowth of the ventral otocyst from embryonic day 11 onwards. Initially, the Sox 2 transcription factor and the Notch ligand Jagl are expressed throughout the thickened portion of the cochlear duct (Fig. 1A) (Ohyama et al., 2010). These genes are gradually downregulated in the abneural side of the duct over the next $36 \mathrm{~h}$, and by E12.5E13.0, the central region of the duct expresses Sox2, the cyclindependent kinase inhibitor p27, and the bHLH transcription factor Hey2 (Fig. 1 A) (Chen and Segil, 1999; Hayashi et al., 2008; Li et al., 2008; Doetzlhofer et al., 2009). This region-termed the prosensory domain-will ultimately give rise to the organ of Corti; it begins to differentiate into hair cells and supporting cells in the midbasal region of the cochlea at E13.5, with differentiation proceeding to the apex of the cochlea over the next few days (Fig. 1 A) (Chen et al., 2002; Lee et al., 2006). Between E12.5 and E13.5, the central prosensory domain $\left(\mathrm{Sox} 2^{+}, \mathrm{Hey} 2^{+}, \mathrm{p} 27^{+}\right.$) (Fig. $1 A, B$ ) is bounded on its neural side by Kölliker's organ $\left(\operatorname{Jag} 1^{+}\right.$, Sox $2^{+}$) (Fig. 1) and on its abneural side by the future outer sulcus, which expresses Bmp4 (Fig. $1 A, B$ ) (Ohyama et al., 2010). At this time, the Notch 1 receptor is expressed throughout the ventral portion of the cochlea duct, with Notch3 expressed at much lower levels (Fig. 1B). 
Canonical Notch pathway signaling involves cleavage of the intracellular domain of Notch receptors, where they travel to the nucleus and form a transcriptional complex with $\mathrm{RBPJ} \kappa$ and MAML proteins. We visualized canonical signaling through the Notch1 receptor using antibodies to the activated Notch1 intracellular domain (N1ICD). Between E12.5 and E13.5, we were unable to detect N1ICD in the prosensory domain of the cochlea, although N1ICD staining could be readily observed in vestibular sensory tissue in the same sections where hair cells and supporting cells are already present (Fig. 1C). N1ICD staining could first be detected in the midbasal region of the cochlea after E13.5, coincident with the differentiation of hair cells and supporting cells. At E14.5, N1ICD staining could be seen in cells adjacent to differentiating hair cells (Fig. 1C). N1ICD staining could also be seen in a subset of supporting cells in the neonatal cochlea (Fig. 1C). These data suggest that canonical signaling through the Notch1 receptor is not occurring in the prosensory domain of the cochlea, but only commences once hair cell and supporting cell differentiation is underway.

\section{The vestibular system is severely} malformed in $R B P j \kappa$ mutant mice

To determine the role of canonical Notch signaling in cochlear prosensory specification and lateral inhibition in the inner ear, we generated a conditional mutation of $R B P j \kappa$ by crossing $R B P j \kappa^{\text {floxed/floxed }}$ mice with Pax2-Cre/+, RBPjK ${ }^{\mathrm{del} /+}$ mice. The Pax2-Cre transgene is expressed throughout the otic placode beginning at E8.5 and therefore induces recombination in the cells that give rise to the inner ear (Ohyama and Groves, 2004). Pax2-Cre, RBPjк del/flox $^{\text {off- }}$ spring lack both wild-type alleles of RBPj $\kappa$ and will be henceforth referred to as RBPjк conditional knock-outs (CKO). Because the Pax2 locus also drives Cre expression in other tissues, such as the midbrain, midbrain neural crest, and kidney, RВРјк CKO mice die at E13.5, likely due to requirements for Notch signaling in vascular development (Cheng et al., 2007).

To first analyze the effects of RBPj $\kappa$ inactivation on the gross morphology of the ear, we paint-filled the inner ears of mutants and wild-type littermates between E11.5 and $\mathrm{E} 13.5$. RBP $\kappa$ inactivation produced severe malformations in the vestibular portion of the inner ear at E13.5 (Fig. 2A). These malformations varied in severity in the 10 mutant ears observed. The least severe phenotype $(n=6)$ had truncations of the vestibular labyrinth, with remnants of all three semicircular canals still present and much reduced saccule and utricle (Fig. 2A). This phenotype was reminiscent of an ear-specific Jag1 conditional mutant phenotype reported previously (Kiernan et al., 2006). In $25 \mu \mathrm{m}$.
E11.5

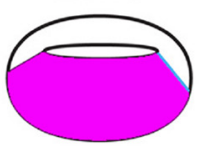

Jag1

Sox2

B
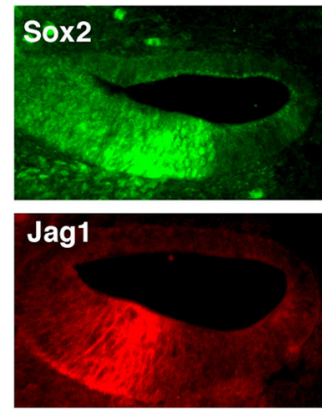

C
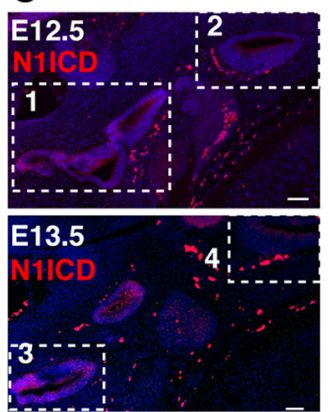

E14.5

Atoh1-GFP

Nites

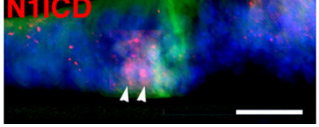

E13

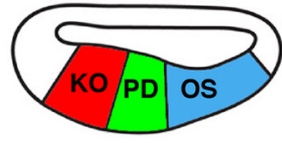

Jag1, Sox2, Notch1

Sox2, p27, Hey2 ,Notch1

Bmp4, Notch1
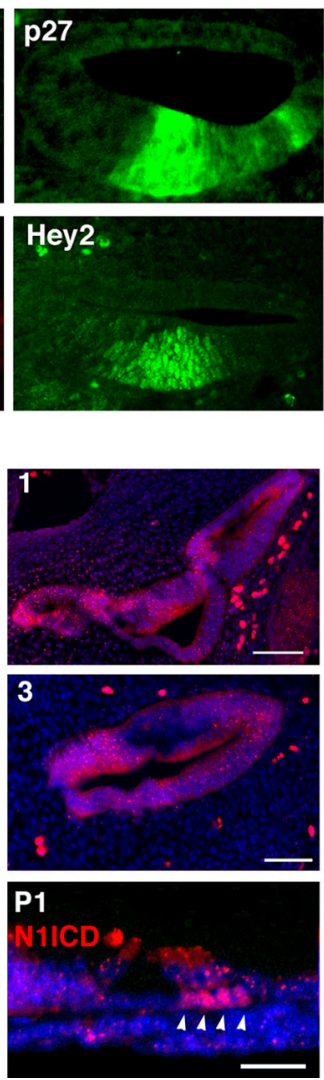

E14.5

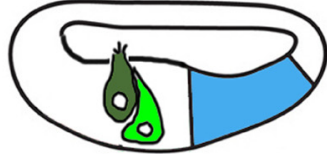

Nascent HCs

Nascent SCs

Notch1, N1ICD, Sox2 p27, Hey/Hes
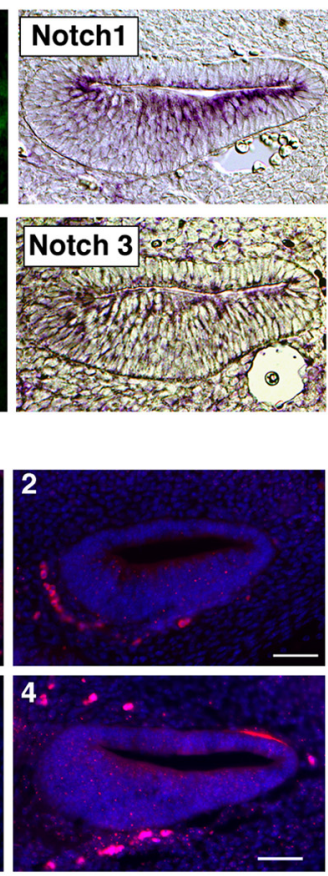

Figure 1. Components of canonical Notch signaling are expressed in the developing cochlea. $\boldsymbol{A}$, Schematic diagram illustrating the differentiation of the cochlea between E11.5 and E14.5. At E11.5, the ventral half of the cochlear duct expresses Jag1 and Sox2 (Ohyama et al., 2010). Between E12.5 and E13.0, this Jag1 ${ }^{+} ;$; Sox2 ${ }^{+}$domain becomes restricted to Kölliker's organ (KO) on the neural side of the cochlear duct. A prosensory domain (PD) develops in the central portion of the duct, expressing Sox2, p27, and Hey2. It is bounded on the abneural side by the future outer sulcus (OS), which expresses Bmp4. At this stage, the entire cochlear duct expresses the Notch1 receptor. As hair cells (HC) and supporting cells (SC) differentiate after E13.5, activation of Notch1 can be observed in supporting cells (C). B , Sections through the cochlear duct of E13.5 embryos. p2 $7^{\text {kip } 1}$ and Sox2 immunostaining label the prosensory domain. Jagged1 and Hey2 label Kölliker's organ and the prosensory domain, respectively. In situ hybridization for Notch 1 and Notch3 show expression throughout the ventral wall of the cochlea, with Notch3 being expressed at low levels. C, Notch1 receptor activation in the cochlea and vestibular system. AtE12.5 and E13.5, the intracellular portion of the Notch1 receptor (N1ICD) can be detected in the vestibular system (boxes 1 and 3) but not in the cochlear duct on the same sections (boxes 2 and 4). Scale bars, $50 \mu \mathrm{m}$. At E14.5, N1ICD (arrowheads) can be detected in cells adjacent to differentiating Atoh1-expressing hair cells. These are likely to become supporting cells. By postnatal day 1, N1ICD is seen in a subset of supporting cells (arrowheads). Scale bar,

the most severe cases $(n=2)$, the whole vestibular portion of the inner ear was reduced to a vestigial fork-shaped structure and contained no remnants of the semicircular canals, ampullae, utricle, or saccule (Fig. 2A). The remaining two mutant ears had an intermediate phenotype (data not shown). The degeneration of the vestibular portion of the ear occurred quite rapidly-at E11.5, the ears of $R B P j \kappa$ mutants were morphologically indistinguishable from their wild-type littermates; at E12.0, defects in the fusion and remodeling of the canal plates started to occur (Fig. $2 \mathrm{~A}$ ). By E12.5, the mutant inner ears were significantly smaller than 
A
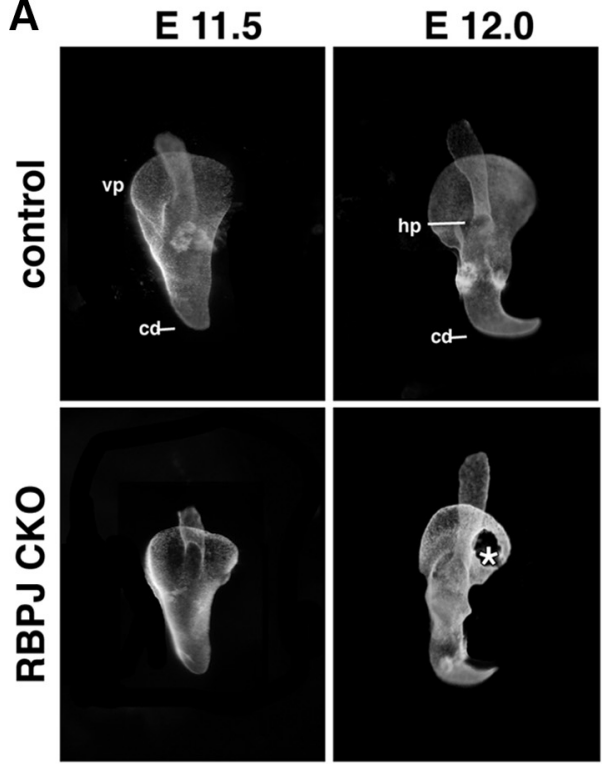

B

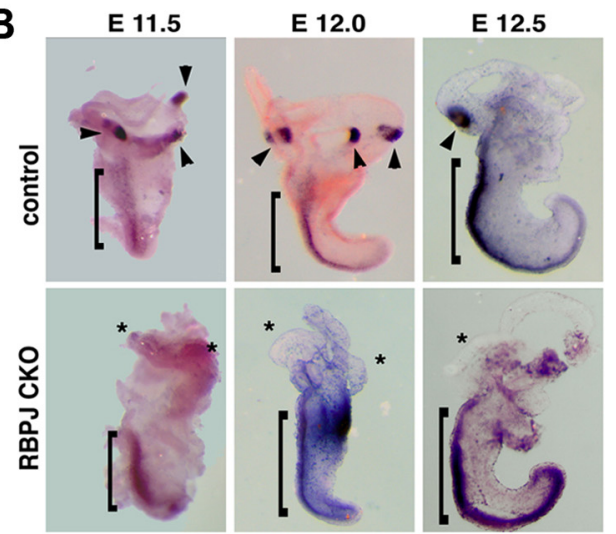

E 12.5
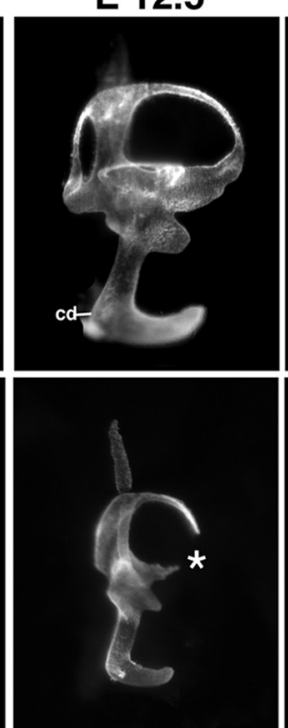

C
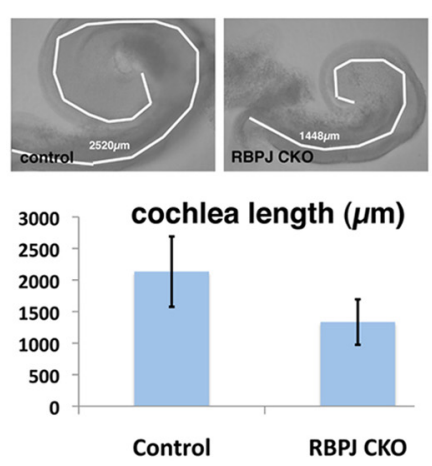

Figure 2. RBPjк mutants develop severe inner ear morphological defects. $\boldsymbol{A}$, Paint-filled inner ears from wild-type and $R B P j \kappa$ CKO embryos between E11.5 and E13.5. The RBPjк CKO displays no morphological defects at E11.5, but begins to show defects in semicircular canal formation atE12.0. AtE13.5, two examples of mutant phenotype are shown, one (a) in which semicircular canal and vestibular sensory organ development are abnormal, and a second (b) in which the vestibular system is entirely absent. ed, Endolymphatic duct; asc, anterior semicircular canal; psc, posterior semicircular canal; Isc, lateral semicircular canal; ut, utricle; sac, saccule; cd, cochlear duct; vp, ventral plate; hp, horizontal plate; asterisks, canal truncations. $\boldsymbol{B}$, Vestibular sensory patches are absent in RBPjк mutants. Whole-mount in situ hybridization with a Bmp4 probe on inner ears dissected from E11.5-E12.5 wild-type and RBPjк mutant embryos detects developing cristae in wild-type embryos (arrowheads) but not in RBPj $\kappa$ mutants (asterisks). Bmp4 continues to be expressed along the abneural side of the cochlear duct in both wild-type and mutant ears (brackets). C, The RBPjк CKO cochlea is shorter than wild-type. Bright field images of control and mutant E13.5 cochleas showing tracings of the cochlear duct using the length measurement function of Axiovision 4.7 software (white lines). The average cochlear length is displayed graphically (RBPjк CKO, $n=7$; control, $n=7$; error bars show SD).

their wild-type counterparts, with gaps in the anterior and lateral semicircular canals and reduction in the size of the ampullae, utricle, and saccule (Fig. $2 \mathrm{~A}$ ).

Notch signaling has been implicated in the development of vestibular sensory patches (Daudet and Lewis, 2005; Kiernan et al., 2006; Daudet et al., 2007; Pan et al., 2010; Neves et al., 2011). Moreover, defects in semicircular canal formation are typically also accompanied by defects in crista formation (for review, see Bok et al., 2007). To determine whether the vestibular defects we observed included a failure of cristae to develop, we examined RВPjк mutants between E11.5 and E12.5 for expression of Bmp4, which marks developing cristae in birds and mice ( $\mathrm{Wu}$ and $\mathrm{Oh}$, 1996; Morsli et al., 1998). Although Bmp4 continued to be expressed along the abneural edge of the developing cochlear duct in $R B P j \kappa$ mutants, we were unable to detect $\mathrm{Bmp} 4^{+}$cristae in any of the $R B P j \kappa$ mutant ears examined (Fig. $2 B$ ).

In all paint-filled RBPjк mutant ears, the auditory portion of the inner ear was present but the overall length of the mutant cochlea was shorter compared with controls and the midbasal portion of the cochlear duct was thicker than the rest of the cochlea (Fig. 2C). At E13, the RBPjк mutant cochlear duct was only $60 \%$ the length of wild-type control (1448 vs 2520 $\mu \mathrm{m}, n=7$ ) (Fig. 2C). These results suggest that canonical Notch signaling is absolutely necessary for the survival of the vestibular portion of the inner ear and that canonical Notch signaling is necessary to establish the correct size and/or outgrowth of the cochlear duct.

\section{A cochlear prosensory domain develops in $R B P$ јк $\mathrm{CKO}$ mice}

Since the cochlea is significantly shorter in RВРјк mutants, we analyzed cochlear development in more detail to look for patterning defects. To determine whether a prosensory region was specified in the absence of canonical Notch signaling, we analyzed a panel of markers expressed in the prosensory region of the cochlea at E13.5. p $27^{\text {kip } 1}$ and Sox 2 were both expressed in the cochleas of RВРjк mutants in the same pattern as in wild-type embryos (Fig. $3 A, B)$. The expression of these markers relative to each other also remained unaffected in the mutants. p $27^{\text {kipl }}$ normally begins to be expressed in the cochlear duct between E12 and E12.5, correlating with the start of cell cycle exit in the prosensory domain (Lee et al., 2006). p27 expression initiated at E12 in both wild-type and $R B P j \kappa$ mutant cochlear ducts (data not shown). Hey2 is another marker for the prosensory domain that we have recently shown is regulated in the neonatal cochlea by FGF, but not Notch signaling (Doetzlhofer et al., 2009). Hey2 expression in the RВРјк mutant cochlea was also similar to controls at E12.5 (data not shown) and E13 (Fig. 3C,D). We also examined markers of Kölliker's organ and the future outer sulcus, which are nonsensory regions of the cochlea immediately adjacent to the prosensory domain on its neural and abneural side, respectively. The expression of Jag1 in Kölliker's organ and Bmp4 in the outer sulcus of RBPjк mutants showed no difference in their expression pattern compared with control embryos (Fig. 3C, left, right). To determine whether the position of Kölliker's organ or the outer sulcus was altered relative to the prosensory domain, we examined the expression of Jag1 or Bmp4 together with the prosensory markers Hey 2 and p2 $7^{\text {kip } 1}$. In both $R B P j \kappa C K O$ and control cochleas, the expression of Jag1 and Bmp4 formed a sharp boundary with the prosensory domain on its neural and abneural sides, respectively (Fig. 3D). Previous studies have shown that Heyl and Hey2 are both ex- 
A

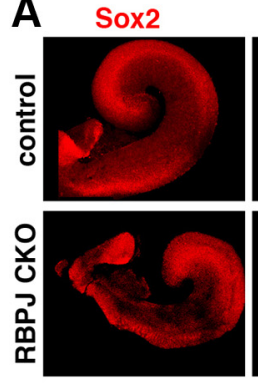

C Jagged1
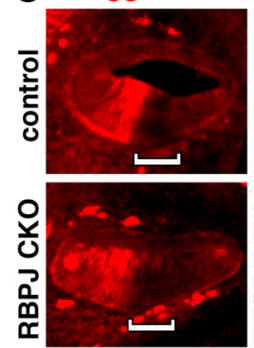

p27

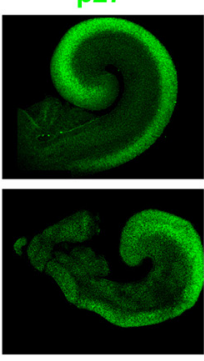

Hey2
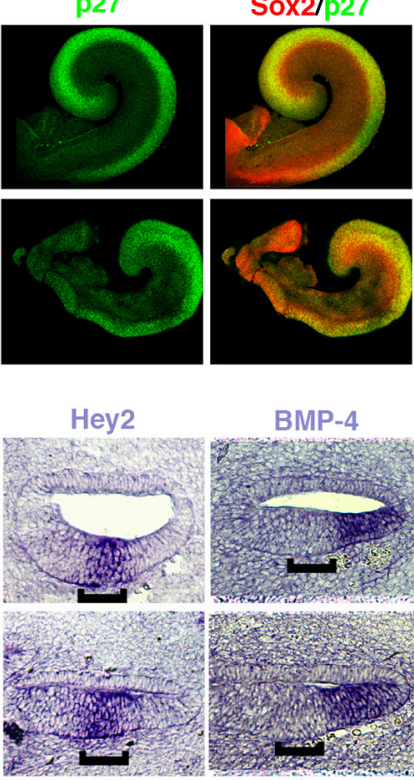

BMP-4
B

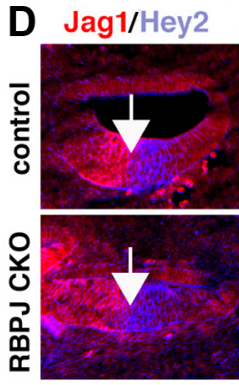

p27
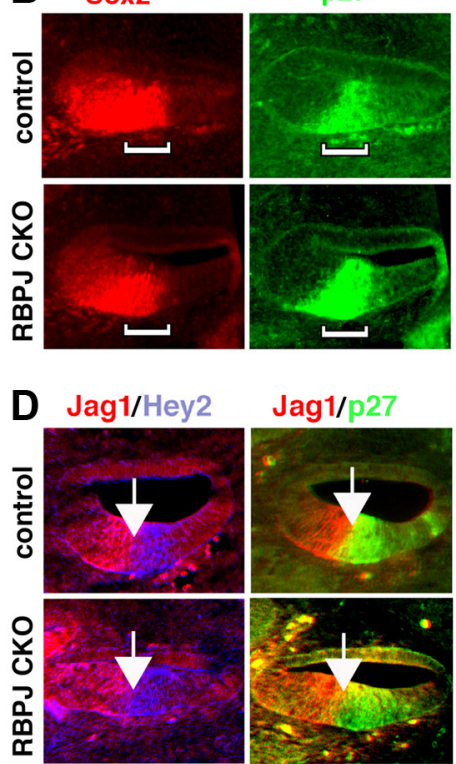

Sox2/p27
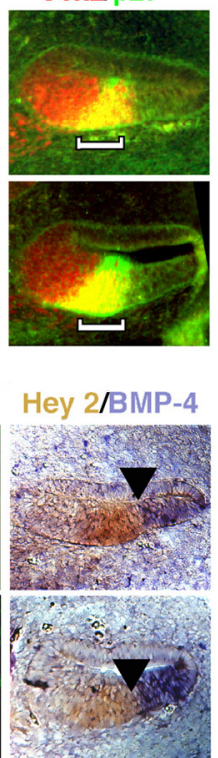

$E$

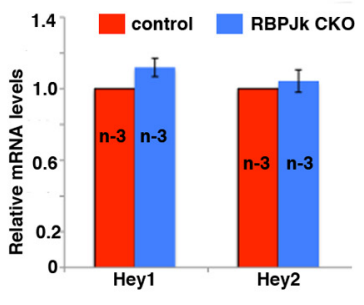

Figure 3. Normal patterning of the E13.5 cochlea in the absence of $R B P j \kappa . A$, Sox2 and p27 ${ }^{\mathrm{kip} 1}$ antibody labeling of whole-mount cochleas from controls (top) or RBPjK CKO (bottom) showing the prosensory domain. $\boldsymbol{B}$, Sox2 and p27 $7^{\text {kip } 1}$ antibody labeling of sections of controls (top) or RBPjK CKO (bottom) showing the prosensory domain (brackets). C, Jagged1 antibody staining and Hey2 and Bmp 4 in situ hybridizations label Kölliker's organ, the prosensory domain, and outer sulcus, respectively. Top, Sections of controls; bottom, RBPjK CKO; brackets, position of the prosensory domain. $\boldsymbol{D}$, The border of the prosensory domain and Kölliker's organ (white arrows) and the border of the prosensory domain and the outer sulcus (black arrowheads) are maintained in controls (top) and RBPjк CKO (bottom). Panels show Jag1 and $27{ }^{\text {kip } 1}$ antibody labeling, Bmp4 in situ hybridization, Hey2 in situ hybridization (left), and Hey 2 immunostaining (right). E, mRNAs for the prosensory markers Hey1 and Hey2 are expressed at comparable levels in E13.5 wild-type and $R B P j \kappa$ mutant cochleas as measured by qPCR.

pressed in the prosensory domain of the cochlea from E12.5 onwards (Hayashi et al., 2008; Li et al., 2008; Doetzlhofer et al., 2009). We observed no significant differences in Heyl or Hey2 mRNA levels in cochleas isolated from E13.5 RВPјк $\mathrm{CKO}$ and wild-type embryos (Fig. 3E). We also confirmed the expression pattern of these genes was unaltered by in situ hybridization (data not shown).

Our results show that the prosensory domain and its adjacent neural and abneural domains develop in the correct location and at the correct times in the absence of canonical Notch signaling. This result was surprising, given that Notch signaling has previously been hypothesized to induce prosensory tissue in the inner ear (Eddison et al., 2000; Daudet and Lewis, 2005; Brooker et al., 2006; Pan et al., 2010). To be sure that our conditional RBPjк mutants efficiently delete the RВPjк gene in a timely manner, we examined the recombination efficiency in Pax2-Cre mice by crossing with a Cre reporter line that expressed EYFP in a Credependent manner (Srinivas et al., 2001). We examined serial sections through the otocyst or cochlea of E10.5 and E13.5 Pax2Cre;Cre reporter embryos. No EYFP-negative cells were found in the ventral half of the otocyst in any section examined. At E13.5, the entire cochlear duct consisted of EYFP-positive cells in every section examined (Fig. $4 A$ ). We also examined RBPJ $\kappa$ protein in sections of E10.5 and E13.0 RBPjк mutants. We could not detect $\mathrm{RBPJ} \kappa$ protein in the otic or cochlear epithelium of $R B P j \kappa \mathrm{mu}-$ tants at either age (Fig. $4 A$ ). In contrast, the mesenchyme surrounding the inner ear of RBPjк mutants-which does not express Pax2, and so does not undergo Cre-mediated recombination-contained abundant RBPJ $\kappa$ protein (Fig. $4 A$ ). Next, we examined RBPjк mRNA levels in E13.5 cochleas from wild-type and $R B P j \kappa$ mutant embryos and compared these to the levels of

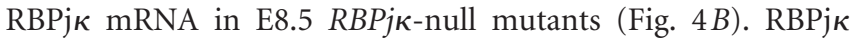
mRNA levels in the cochlea of conditional mutants were virtually undetectable and not significantly different from those detected in E8.5 null embryos. Our results demonstrate that the Pax2-Cre transgene is able to efficiently disrupt RBPJ $\kappa \mathrm{mRNA}$ and protein expression in the cochlear anlagen by E10.5, $48 \mathrm{~h}$ before the formation of the prosensory domain of the cochlea, defined by the onset of p27 expression and cell cycle exit. Thus, the formation of the prosensory domain in $R B P j \kappa$ mutants is not simply due to a failure to efficiently delete the $R B P j \kappa$ gene, but rather suggests that prosensory induction can proceed in the absence of RВРјк.

As the prosensory domain differentiates to generate hair cells and supporting cells, canonical Notch signaling is activated in supporting cells by lateral inhibitory signaling from hair cells, likely mediated by Delta 1 and Jagged 2 ligands. Notch signaling in supporting cells is revealed by the expression of Notch target genes such as Hes1, Hes5, Hey1, and HeyL. To determine whether loss of RBPјк affects the expression of Hes and Hey genes in differentiating supporting cells, we cultured E13.5 wild-type and RВРјк mutant cochleas for $2 \mathrm{~d}$ and measured relative levels of these genes by qPCR. Levels of Hes1, Hes5, Hey1, and HeyL mRNA were all significantly downregulated in $R B P j \kappa$ mutant cochleas relative to wild-type embryos (Fig. 4C). We observed similar results when wild-type E13.5 cochleas were cultured for $2 \mathrm{~d}$ in the presence of the gamma secretase inhibitor DAPT, which blocks Notch signaling (Fig. 4C). Significantly, we did not observe downregulation of Hey 2 in either RBPjк mutant cochleas or in wild-type tissue cultured in DAPT (Fig. 4C). This is consistent with previous work from our laboratory showing that Hey2 is not regulated by the Notch signaling pathway in the cochlea (Doetzlhofer et al., 2009).

\section{$\mathrm{RBPj} \kappa$ is required for survival but not for differentiation of the organ of Corti}

Our results in Figures 3 and 4 demonstrate that markers for the prosensory region of the cochlea are expressed the absence of canonical Notch signaling. However, the prosensory domain is 



Figure 4. Efficient conditional inactivation of RBPj $\kappa$ by Pax2-Cre mice. A, Pax2-Cre transgenic mice were crossed to Rosa-YFP reporters to analyze the efficiency of recombination. Embryos were sectioned at E10.5 or E13.5 and all sections analyzed showed $100 \%$ recombination in the ventral otocyst and cochlear duct (top). The absence of $\mathrm{RBPj} \kappa$ protein was confirmed by immunostaining in controls and conditional mutants at the same ages (middle and bottom). $\boldsymbol{B}, \mathrm{RBPj} \kappa$ mRNA levels of E13.5 conditional mutant cochleas or E8.5 null embryos were compared with controls by quantitative PCR. RBPj $\kappa$ mRNA levels in the E13.5 conditional mutant cochleas are undetectable compared with wild-type. A similar result is seen in E8.5 RBPj $\kappa$-null embryos compared with wild-type embryos of the same age (all measurements were performed in triplicate; $n=3$ in each case). C, E13.5 wild-type and RBPjк mutant cochleas were cultured for $2 \mathrm{~d}$ and assayed for expression of Hes1, Hes5, Hey1, Hey2, and HeyL mRNA by qPCR. In addition, extra wild-type cultures were grown in the presence of DAPT for $2 \mathrm{~d}$ to inhibit Notch signaling. All Hes and Hey genes are significantly downregulated in RBPjк mutants and DAPT-treated cultures, with the exception of Hey2. All measurements were performed in triplicate; $N=7$ for Hes and Hes5; $n=4$ for Hey1, Hey2, and HeyL. Error bars represent SEM.

also defined functionally as the region of the cochlea containing the progenitor population for hair cells and supporting cells that form the organ of Corti. We therefore examined whether the prosensory region we observed in $R B P j \kappa \mathrm{CKO}$ mice can differentiate into these cell types. We cultured E13.5 mutant and control cochleas to allow the differentiation of hair cells and supporting cells to take place. Dissected E13.5 cochleas were placed in culture in chemically defined medium for $48 \mathrm{~h}$ and analyzed for the presence of hair cells and supporting cells (Fig. $5 A-H$ ). Hair cells differentiated in the $R В Р ј \kappa$ mutant cochlea in a midbasal to apical pattern, as shown by Myo6 or parvalbumin staining. However, the hair cells were not organized in the characteristic pattern of three rows of outer hair cells and one row of inner hair cells (Fig. $5 A, E$ ). Supporting cells also differentiated, as shown by Prox 1 staining, but their number was reduced (Fig. $5 B, F$ ). In control cultures, Proxl labeled five rows of supporting cells, whereas in RBPjk mutants, we observed only two or three rows of Prox1-labeled cells. These Prox $1+$ supporting cells expressed $p 75^{\text {LNGFR }}$ (data not shown), suggesting they are pillar cells, which we previously showed are not responsive to Notch-mediated lateral inhibition (Doetzlhofer et al., 2009). The observed reduction in the number of supporting cells is consistent with a model of Notch-mediated lateral inhibition in the organ of Corti, whereby hair cells inhibit supporting cells from adopting a hair cell fate. Nevertheless, we did not observe an obvious increase in the number of hair cells that would be predicted by the lateral inhibition model. Rather, we saw fewer hair cells in $R B P j \kappa$ mutants ( $32 \pm 5$ hair cells/100 $\mu \mathrm{m}, n=7$; compared with $58 \pm 2$ hair cells $/ 100 \mu \mathrm{m}$ in controls, $n=4)$.
It is possible that in the absence of RBPjк function, hair cells differentiate from prosensory progenitors but die shortly after differentiation occurs. To test whether cell death is responsible for the reduced numbers of hair cells in $R B P j \kappa$ mutant cochleas, we analyzed cell death in wild-type and mutant cochleas that had been cultured for 2 or 4 DIV. After $2 \mathrm{~d}$, we observed a large increase in cell death in the sensory region of $R B P j \kappa$ mutant cochleas, as shown by activated caspase- 3 staining (Fig. 5C,G). We confirmed this result with TUNEL assays (Fig. $5 D, H$ ). After 4 DIV, hair cells were absent from the basal half of the RBPjк mutant cochleas and cell death continued in the hair cells in the apical half (Fig. 5I-L). The timing and pattern of caspase- 3 staining suggests that, in the absence of canonical Notch signaling, a wave of cell death follows the basal to apical gradient of differentiation in the organ of Corti. This result indicates that RBPj $\kappa$ is required for the survival of the differentiated hair cells in the sensory epithelium of the organ of Corti.

To confirm that no precocious differentiation of hair cells and supporting cells occurs in the absence of canonical Notch signaling, we stained sections of E13.5 $R B P j \kappa$ mutant inner ear with antibodies against Myo6 and Prox1. All cochlear sections were negative for these markers (data not shown), suggesting that RBPزк does not repress sensory differentiation in the progenitor population before differentiation of the organ of Corti. We also examined the expression of Atohl, the first gene to be expressed in differentiating hair cells. Atohl expression was first detected in the midbasal region of both E13.5 wild-type and $R B P j \kappa \mathrm{CKO}$ cochleas after $1 \mathrm{~d}$ in culture (Fig. $5 M, N)$, although the Atoh1 expression domain appeared wider in $R B P j \kappa \mathrm{CKO}$ tissue (Fig. $5 M^{\prime}, N^{\prime}$ ). This broadened domain is consistent with the overproduction of hair cells seen in other Notch pathway mutants (Kiernan et al., 2005a).

\section{Prosensory specification occurs in the cochlea of other Notch pathway mutants}

Induction of prosensory patches by Notch signaling in the chicken and mouse inner ear has been proposed to occur through the Jag1 ligand (Daudet and Lewis, 2005; Brooker et al., 2006; Kiernan et al., 2006). Previous studies analyzed the cochlear phenotype of Jag1 conditional mutant mice at the onset of hair cell differentiation and, although hair cell differentiation was perturbed, hair cells nevertheless differentiated to some extent in these mutants (Brooker et al., 2006; Kiernan et al., 2006). We therefore examined the expression of prosensory markers in younger embryos in which Jag1 had been conditionally inactivated with Pax2-Cre mice. We analyzed the expression of Sox2, p27, Hey2, Jag1, and Bmp4 in E13.5 cochleas of Jag1 CKO mice and compared them with RBPjк mutants (Fig. $6 \mathrm{~A}$ ). All prosensory domain markers were expressed in the correct location in Jag1 mutants, suggesting that Jag1 signaling though the Notch receptor is not necessary for the specification of the prosensory 


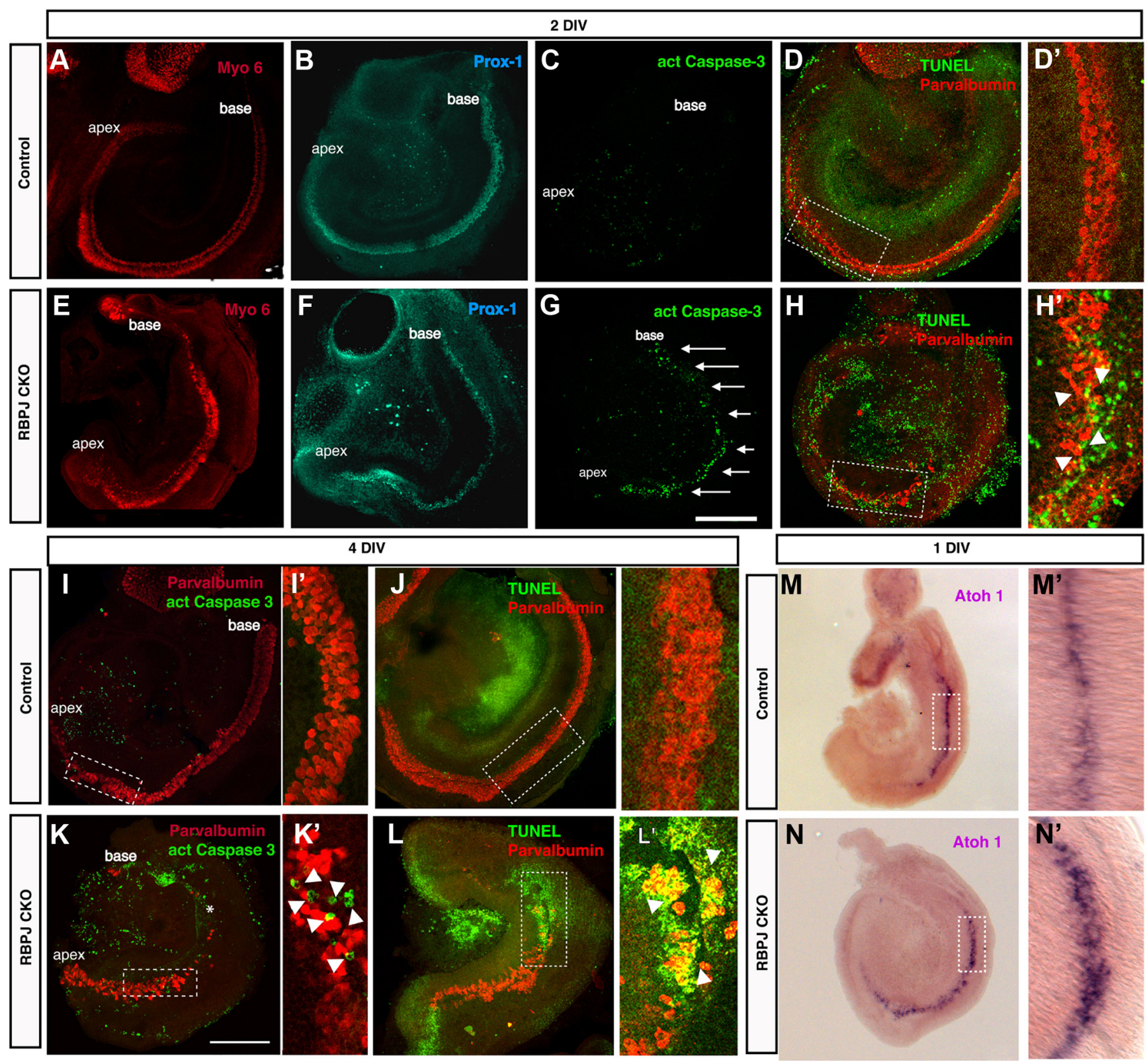

Figure 5. Cochlear hair cells form and subsequently die in the absence of RBPj $\kappa . A-L, E 13.5$ cochleas were cultured in a defined medium for $2 \mathrm{~d}(\boldsymbol{A}-\boldsymbol{H})$ or $4 \mathrm{~d}(\boldsymbol{I}-\boldsymbol{L})$. Cultures were stained with an antibody against activated caspase-3 $(\boldsymbol{C}, \boldsymbol{G}, \boldsymbol{I}, \boldsymbol{K})$ or TUNEL assays were performed $(\boldsymbol{D}, \boldsymbol{H}, \boldsymbol{J}, \boldsymbol{L})$ to analyze cell death. Hair cells were labeled with antibodies to Myo6 $(\boldsymbol{A}, \boldsymbol{E})$ or parvalbumin $(\boldsymbol{D}, \boldsymbol{H}, \boldsymbol{I}, \boldsymbol{K}, \boldsymbol{J}, \boldsymbol{L})$. Supporting cells were labeled with Prox1 antibodies $(\boldsymbol{B}, \boldsymbol{F})$. The sensory epithelium in $R B P j \boldsymbol{K}$ mutants showed a significant increase in cell death $(\boldsymbol{G}$, arrows; $\boldsymbol{H}^{\prime}, \boldsymbol{K}^{\prime}, \boldsymbol{L}^{\prime}$, arrowheads) compared with controls $\left(\boldsymbol{C}, \boldsymbol{D}, \boldsymbol{D}^{\prime}, \boldsymbol{I}, \boldsymbol{I}^{\prime}, \boldsymbol{J}, \boldsymbol{J}^{\prime}\right) . \boldsymbol{K}$, asterisk, Basal portion of the cochlea where hair cells died. $\boldsymbol{D}^{\prime}, \boldsymbol{H}^{\prime}, \boldsymbol{I}^{\prime}, \boldsymbol{K}^{\prime}, \boldsymbol{J}^{\prime}, \boldsymbol{L}^{\prime}$, Confocal planes through the dotted boxes in $\boldsymbol{D}, \boldsymbol{H}, \boldsymbol{I}, K, \boldsymbol{J}, \boldsymbol{L}$, respectively, showing activated caspase-3 staining or positive TUNEL signal in the sensory epithelium of $R B P j \kappa\left(K O\right.$ cultures ( $\boldsymbol{H}^{\prime}$, arrowheads). Scale

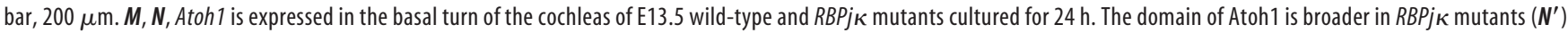
compared with wild-type cochleas $\left(\boldsymbol{M}^{\prime}\right)$.

domain (Fig. 6A). Bmp4, a marker of the future outer sulcus on the abneural side of the prosensory domain, was also expressed in the same pattern as in controls, suggesting that the overall patterning of the cochlea is not disrupted in the absence of Jag1-Notch signaling. At E14.5, we continued to observe Hey2, p27, and Sox2 expression in all three turns of the Jag1 mutant cochlea (Fig. 6B).

We also compared RBPjк mutants with ear-specific conditional mutants of Pofut1, an $O$-fucosyltransferase that has been reported to be required for Notch signaling in a variety of cellular contexts (Okajima and Irvine, 2002; Sasamura et al., 2003; Shi and Stanley, 2003; Okamura and Saga, 2008; Schuster-Gossler et al., 2009). Markers of the cochlear prosensory domain were ex- pressed normally in Pofut1 CKO mice (Fig. 6A). In addition, Jag1 and $B m p 4$ were expressed normally on the neural and abneural sides of the prosensory domain, respectively (Fig. 6A).

Although prosensory domain markers were observed in Jag1 and Pofut 1 mutants, we saw later defects in hair cell patterning in cochlear cultures derived from both mutants (Fig. 6C). Pofut1 mutant cochleas showed supernumerary hair cells similar to those observed in Notch1 mutants (Kiernan et al., 2005a), whereas cultured Jag1 mutant cochleas showed a loss of outer hair cells and duplicated inner hair cells (Brooker et al., 2006; Kiernan et al., 2006). The cochlear phenotype of neonatal Jag1 mutants was also the same as that previously published (data not 
A Sox2

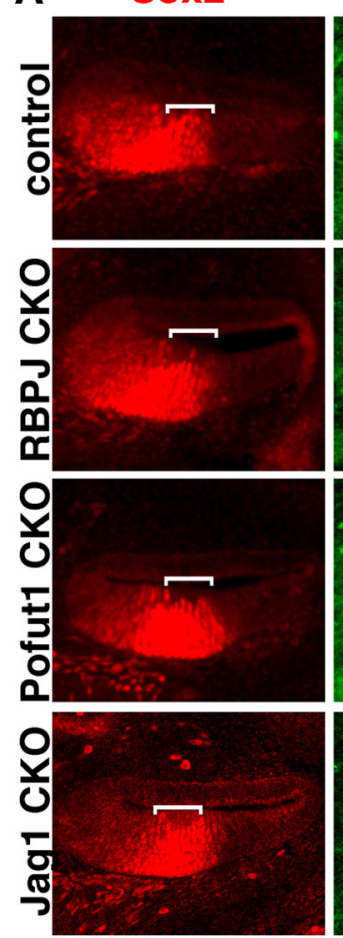

B

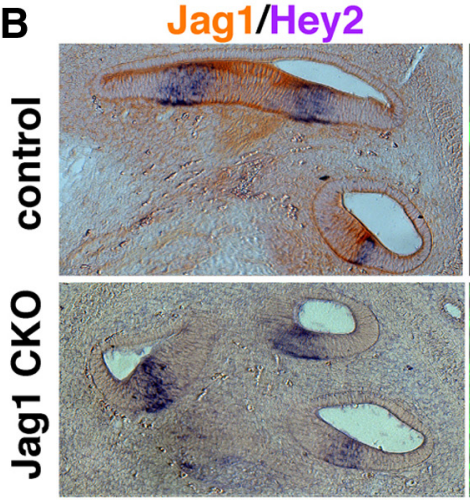

C

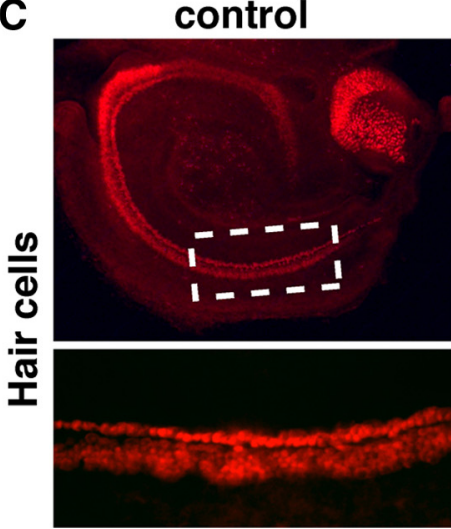

p27
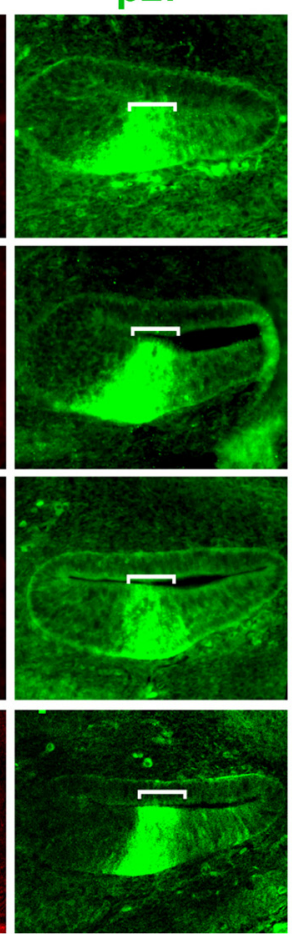

Sox2/p27
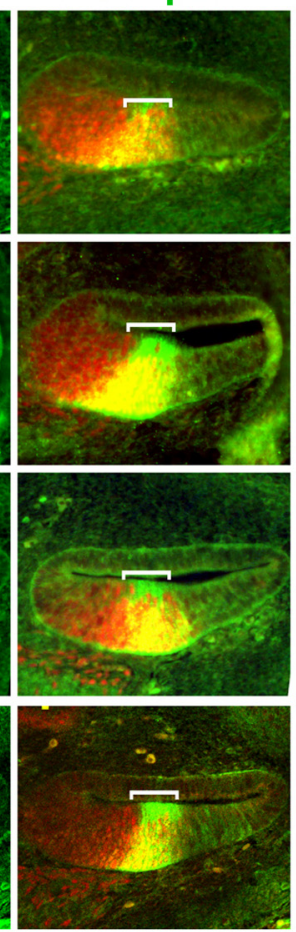

p27

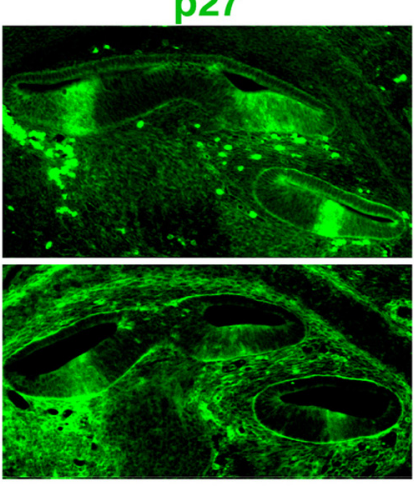

RBPJ CKO

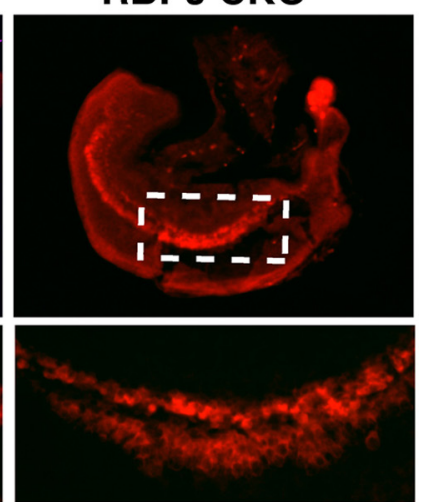

Hey2
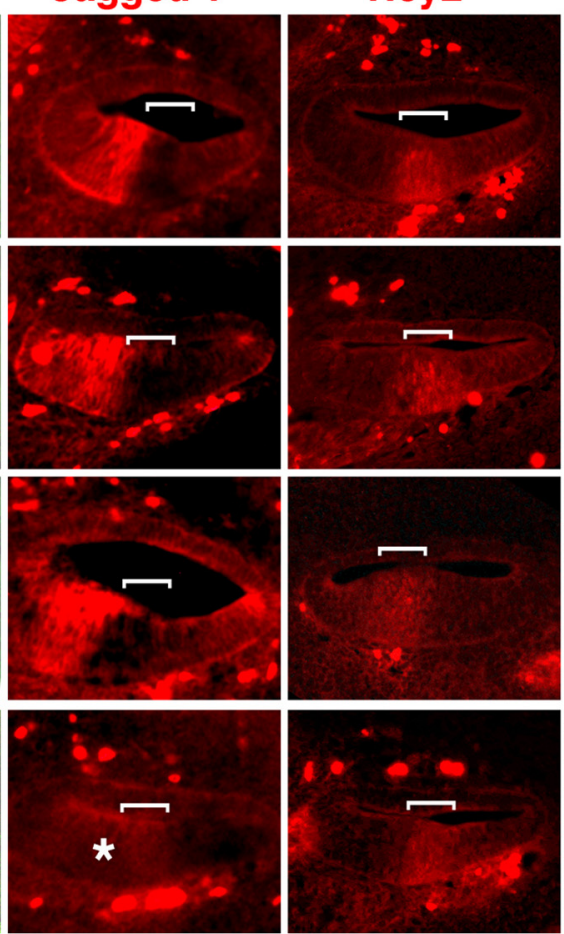

Sox2
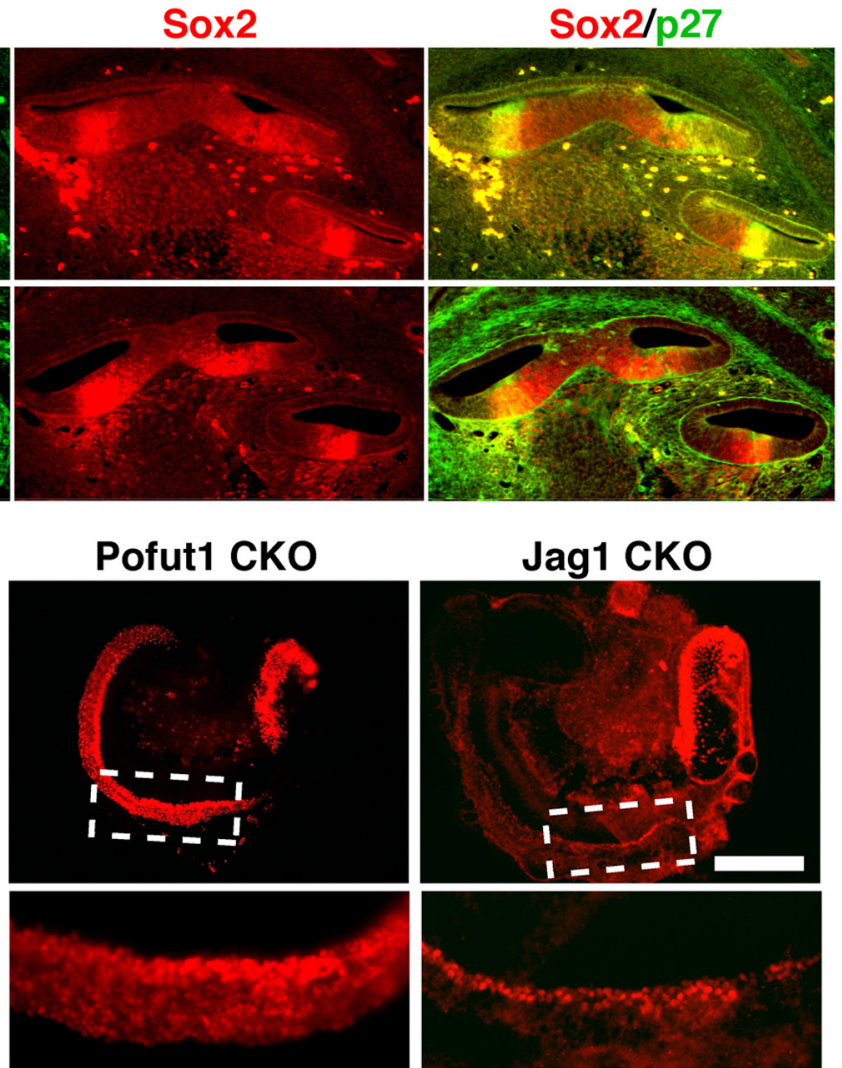
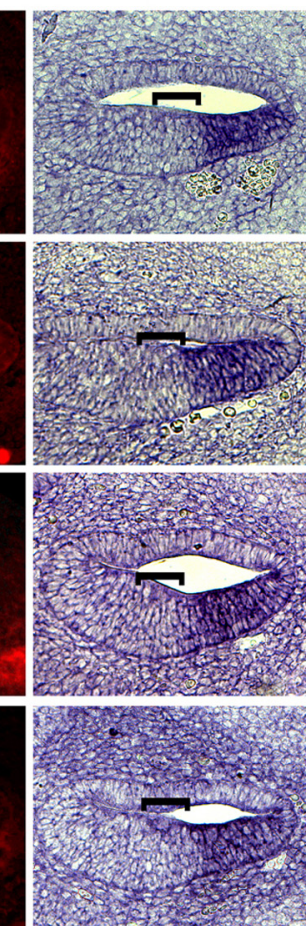

Jag1 CKO

BMP-4

Sox $2 / p 27$

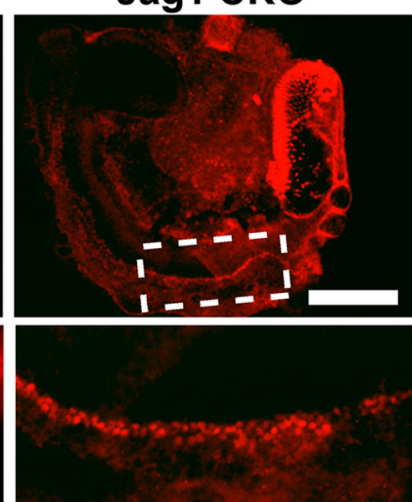

Figure 6. The prosensory domain of the cochlea is correctly specified in RBPJ $\kappa$, Pofut1, and Jag1 mutants. A, Sections through the cochlear duct of E13.5 wild-type and RBPjк, Pofut1, and Jag1 mutant embryos. The prosensory domain (brackets) was labeled with antibodies to $\mathrm{p} 27^{\text {Kip1 }}$ and in situ hybridization for Hey2, Kölliker's organ was labeled with antibodies to Jagged1, and the outer sulcus identified by in situ hybridization for Bmp4. Sox2 expression labeled both the prosensory domain and part of Kölliker's organ. All markers are expressed in normal patterns in all three mutants, with the exception of Jag1, which is absent in Jag 1 CK0 embryos (asterisk). B, Hey2 in situ hybridization in sections from control and Jagged 1 CK0 E14.5 embryos. Jagged1 immunostaining is shown in brown. Hey $2 \mathrm{mRNA}$ is still expressed in the differentiating prosensory domain (left). p27 and Sox2 immunostaining showing expression in the differentiating prosensory domain of control and

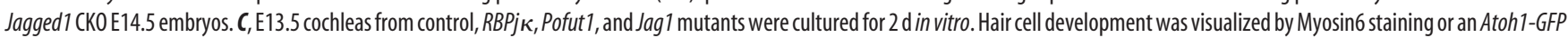
reporter (Pofut1). Scale bar, $200 \mu \mathrm{m}$. 
shown) (Brooker et al., 2006; Kiernan et al., 2006). These data suggest that, although mutations in Jag1 and Pofut1 can affect the differentiation of hair cells and supporting cells, they do not appear to disrupt the induction of the prosensory domain.

\section{Notch signaling is not sufficient to direct sensory specification in the mammalian cochlea}

Two previously published lines of evidence suggest that Notch signaling is sufficient to direct a prosensory fate in the cochlea. First, overexpression of the N1ICD can upregulate expression of Sox 2 in the greater epithelial ridge (Dabdoub et al., 2008). However, Sox2 labels not only the prosensory region, but also portions of Kölliker's organ and later the differentiated organ of Corti, so it is not a completely specific marker for prosensory fate following Notch activation. Second, overexpression of N1ICD at early stages of ear development can induce ectopic sensory patches in the avian basilar papilla and nonsensory regions of the mouse cochlea (Daudet and Lewis, 2005; Pan et al., 2010). We tested whether N1ICD overexpression later in the developing cochlea could induce prosensory or sensory fates. We took advantage of a Cre-inducible mouse line that allows expression of a N1ICD-IRESGFP sequence (Murtaugh et al., 2003). We crossed this line to mice carrying a tamoxifen-inducible version of Cre recombinase, CreER, driven by a strong CMV promoter (Hayashi and McMahon, 2002). N1ICD can be activated in tissue from double transgenic offspring by the addition of tamoxifen to the culture medium. Because the N1ICD-IRES-GFP construct is knocked into the Rosa locus, it has the additional advantage of expressing moderate levels of N1ICD, as opposed to the high overexpression levels achieved by electroporation. (Fig. 7A). We cultured E13.5 N1ICD;CMV-CreER cochleas for $48 \mathrm{~h}$ in the presence or absence of tamoxifen. In all cases, a cultured cochlea from one ear was treated with tamoxifen while the contralateral cochlea receiving vehicle only served as a control. We first verified that Sox 2 was upregulated in Kölliker's organ in the presence of ectopic N1ICD (Fig. $7 B$ ), which indicated that transgenic overexpression of N1ICD has the same effect on Sox 2 as the previously described technique using N1ICD electroporation (Dabdoub et al., 2008). Hey2 is a marker for the prosensory domain of the cochlea before hair cell differentiation and subsequently becomes restricted to pillar cells (Doetzlhofer et al., 2009). We did not observe any upregulation of Hey2 after N1ICD overexpression in our culture system in four independent experiments (Fig. $7 B$ ). Next, we tested whether N1ICD overexpression could induce ectopic sensory patches in a

C
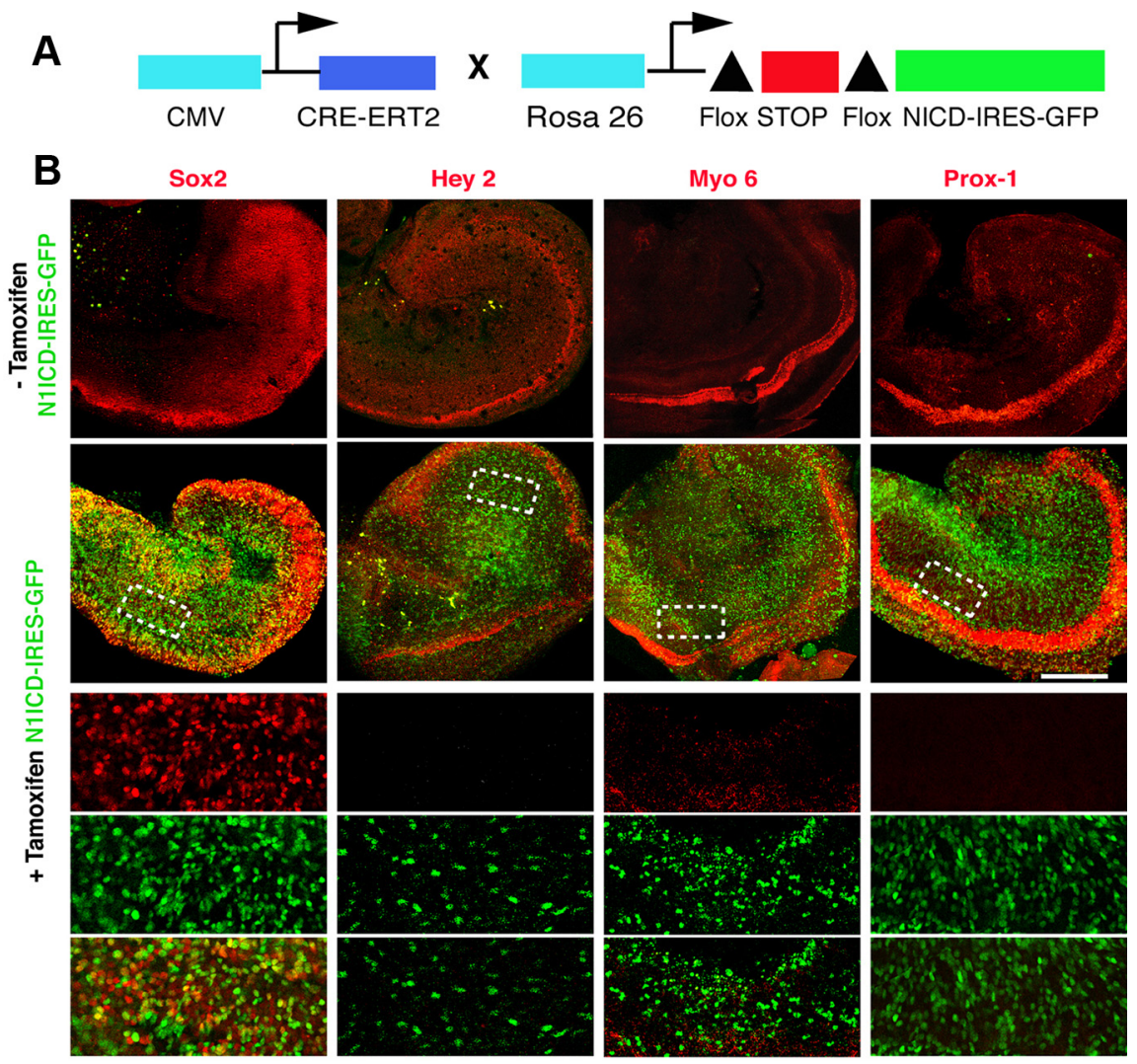

wild type cochlea
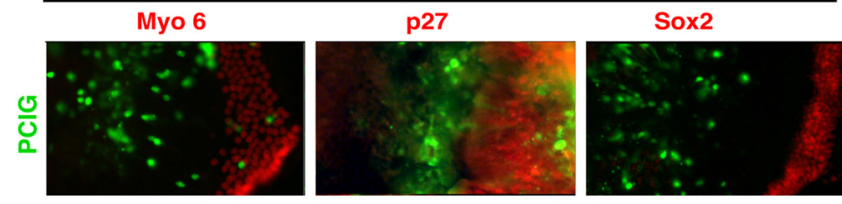

RBPJk CKO cochlea
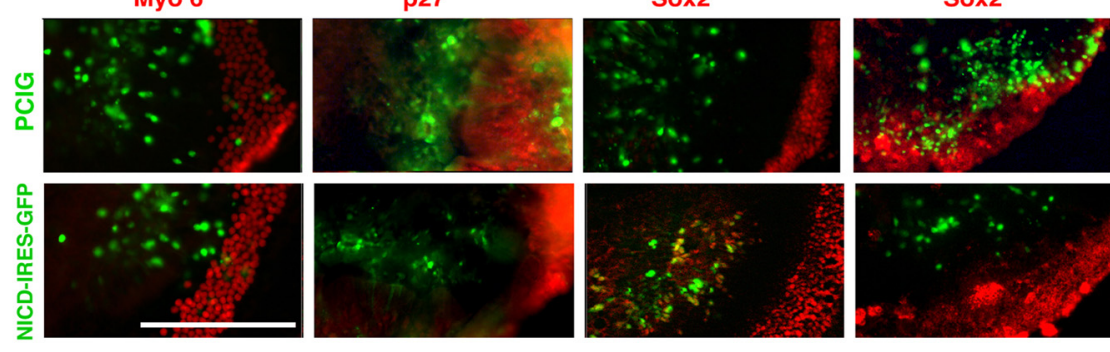

Figure 7. Activation of Notch signaling is not sufficient to induce prosensory or sensory fates in the cochlea. $\boldsymbol{A}$, The diagram shows the tamoxifen-inducible system we used to express N1ICD throughout the cochlea. Upon addition of tamoxifen, Cre-ER removes a floxed stop cassette and allows expression of N1ICD and GFP driven by the Rosa26 promoter. B, E13.5 N1ICD-IRES-GFP, Cre-ER cochleas were cultured in the presence or absence of tamoxifen and allowed to develop for $48 \mathrm{~h}$. We analyzed the expression of Sox2, Hey2, Myo6, and Prox1 by antibody staining (red). GFP expression was present in cells that expressed ectopic N1ICD. The bottom three rows show higher-magnification confocal planes of the dotted boxes above, showing the red channel (marker), green channel (GFP), and overlays. Only Sox2 was upregulated in response to ectopic N1ICD expression. C, E13.5 cochlear explants wid-type mice were electroporated with a GFP control (PCIG) or an N1ICD-IRES-GFP construct, cultured, and examined for expression of Myosin 6 ( $96 \mathrm{~h}$ culture) or p27 and Sox2 (48 h culture). Although Sox 2 is induced by N1ICD overexpression, no ectopic Myosin 6 or p27 cells are seen in the electroporated region. However, Sox2 was not induced when N1ICD was electroporated into RBPj $\kappa$ mutant cochleas. Scale bars, $200 \mu \mathrm{m}$.

way similar to that reported in the chick basilar papilla (Daudet and Lewis, 2005). We examined the presence of ectopic hair cells or supporting cells by immunostaining with Myosin6 or Prox-1, respectively. We found no ectopic hair cells or supporting cells in the cultured explants following N1ICD overexpression in four independent experiments (Fig. $7 B$ ). Finally, we repeated the experiments of Dabdoub and colleagues (2008) by electroporating a N1ICD construct into the greater epithelial ridge of cultured E13.5 cochleas and cultured the explants for $96 \mathrm{~h}$. Once again, we observed no expression of hair cell (Myosin 6) or supporting cell (p27 or Hey2) markers (data not shown), although we again saw 
upregulation of Sox 2 protein (Fig. 7C). Electroporation of N1ICD into RBPjк mutant cochleas did not induce Sox2 (Fig. $7 C$ ), suggesting that N1ICD regulates Sox 2 expression through a canonical, RBPJ $\kappa$-dependent process. Together, our results suggest that ectopic activation of Notch signaling in the developing cochlea is not sufficient to promote prosensory or sensory fates.

\section{Discussion}

Notch signaling has been proposed to play two roles in sensory cell formation in the inner ear: specifying the fine-grained pattern of hair cells and supporting cells through lateral inhibition; and an earlier, less-well characterized role in the induction of prosensory patches, likely through signaling by Jagged/Serrate ligands. To determine whether canonical Notch signaling induces the prosensory domain of the cochlea, we conditionally inactivated RBPjк, the transcriptional mediator of canonical Notch signaling. Our results suggest that canonical Notch signaling is not necessary for prosensory specification in the cochlea. However, we found that RBPjк is essential for the survival of organ of Corti epithelium and for vestibular morphogenesis. We also show that, in contrast to what has been described in the chick basilar papilla, Notch activation in the mammalian cochlea is not sufficient to induce sensory cell fates.

\section{Is canonical Notch signaling necessary for cochlear prosensory specification?}

We present several lines of evidence suggesting that canonical Notch signaling is not necessary for prosensory specification in the mouse cochlea. First, markers of the prosensory region such as p $27^{\text {kip } 1}$, Sox 2 , and Hey 2 are expressed with the correct timing and location between at E12.5 and E13.5 in RBPjк mutants (Fig. 3). Second, our N1ICD antibody staining data (Fig. 1C) and data from Murata and colleagues (2006) show that signaling through the major Notch receptor in the cochlea, Notch1, cannot be visualized in the developing prosensory domain and is only observed at the onset of hair cell differentiation. Finally, hair cells and supporting cells differentiate in the cochlea of RВРјк mutants (Fig. 5) but later die, suggesting that prosensory progenitors are present in these animals.

Although our data suggest that canonical Notch signaling is not necessary for cochlear prosensory formation, they do indicate a role for canonical Notch signaling in inner ear morphogenesis. $R B P j \kappa$ mutants show a range of severe vestibular malformations of the vestibular system at E13.5, together with a shortened cochlea. The most severe phenotype we observed shows a complete lack of vestibular development (Fig. 2). It has been proposed that the presumptive cristae induce the formation of the associated nonsensory structures (Cantos et al., 2000), suggesting that the defects in semicircular canal formation could have their origin in the absence of the vestibular sensory patches. Canonical Notch signaling through RBPj $\kappa$ may be required for the specification of sensory progenitors in the mammalian vestibular system. Alternatively, RBPјк may be necessary for sensory patch survival, and death of sensory tissue may be the cause of the severe morphological abnormalities observed. Our observation that BMP4 ${ }^{+}$ cristae cannot be detected in the mutants would support either hypothesis; we are currently analyzing the development of the vestibular sensory organs in RВРјк mutants in more detail.

The cochlear prosensory domain develops at the correct time and location in RBPjк mutants; however, the cochlea itself is nevertheless 40\% shorter at E13.5 (Fig. 2A,B). Sections through the mutant cochlea show that the prosensory domain is of a comparable cross-sectional area to controls and is similarly bounded by nonsensory regions expressing markers of the developing inner and outer sulci (Fig. 3). In addition, all parts of the RBPjK mutant ear appear smaller at least as early as E1 1.5 (Fig. 2A). This suggests that the shortening of the mutant cochlea may be a global phenomenon because of a reduction in the number of inner ear progenitors at early developmental stages, rather than reflecting a specific role for canonical Notch signaling in prosensory domain induction. Consistent with this idea is previous work from our laboratory showing that Notch signaling acts very early in the development of the ear to augment canonical Wnt signaling in specifying the size of the otic placode (Jayasena et al., 2008).

Our finding that the prosensory domain is present in the RBPJk mutant cochlea appears to conflict with a previously proposed role for Jag1-Notch signaling in cochlear prosensory specification (Brooker et al., 2006; Kiernan et al., 2006). In these studies, both p2 $7^{\text {kip } 1}$ and Sox 2 were downregulated or absent in the basal part of the cochlea of Jag1 conditional mutants. One explanation for the discrepancy between our work and these studies may be slight difference in the ages of embryos examined. Since the basal region of the cochlea differentiates before apical regions (Chen et al., 2002; Kiernan et al., 2005b), it is possible that the $\mathrm{p} 27^{-}$/ Sox $2^{-}$basal region observed by Kiernan and colleagues (2006) in the Jag1 mutant cochlea at E14.5 reflects a lack of differentiated supporting cells rather than a lack of a prosensory domain. Indeed, we still observe p27 and Sox2 expression in E14.5 Jag1 mutant cochleas (Fig. 6B). The fact that p27 and Sox2 are still expressed in the apical portion of the E14.5 Jag1 mutant cochlea (Brooker et al., 2006; Kiernan et al., 2006) seems to favor this idea. Recently, a second study where RBPJk was deleted in the inner ear with a different Cre driver also reported the formation of a prosensory domain capable of producing Atoh1-expressing hair cells (Yamamoto et al., 2011), which is in agreement with the results reported here.

\section{Is Notch signaling sufficient to induce sensory tissue in the ear?}

Previous studies suggest that activation of the canonical Notch signaling pathway by ectopic expression of the Notch1 intracellular domain is able to generate ectopic sensory tissue in both birds and mammals (Daudet and Lewis, 2005; Pan et al., 2010). Moreover, ectopic expression of Jag1 is able to stabilize Sox2 expression, although it appears unable to induce it de novo (Neves et al., 2011). Our results show that activation of Notch signaling in the mouse E13.5 cochlea is not sufficient to elicit hair cell or supporting cell fates in the nonsensory regions of the mammalian cochlea. Ectopic activation of N1ICD failed to induce hair cell (Myo6), supporting cell (Prox1), or prosensory (Hey2, p27) markers, although we observed a strong upregulation of Sox2, as previously reported (Dabdoub et al., 2008). Since Sox 2 is normally expressed in the prosensory region, Kölliker's organ, and later in supporting cells, it is difficult to unambiguously determine the identity of the Sox $2^{+}$cells seen in our experiments.

It is possible that Notch activation is able to specify a generic prosensory phenotype characterized by Sox 2 expression, but that additional signals are required to establish a cochlear prosensory phenotype. In this regard, we suggest that the mammalian organ of Corti is a more evolutionarily derived structure than other sensory regions in the ear, and its development may differ from vestibular tissue in mammals and from all inner ear sensory tissue in birds. For example, Jag1 and Bmp4 are strongly expressed in all Sox $2^{+}$prosensory patches of birds and the cristae in mammals (Wu and Oh, 1996; Morsli et al., 1998) and Jag1 signaling is able 
to stabilize the Sox $2^{+}$cell state in birds (Neves et al., 2011). However, in mammals, Jag1 and Bmp4 are excluded from and delimit the Hey $2^{+} ; \mathrm{p} 27^{+}$;Sox $2^{+}$cochlear prosensory domain as it is induced (Fig. 1) (Chen et al., 2002; Ohyama et al., 2010), and recent work from our group has shown that Bmp4 actively suppresses Jag1 expression in the developing cochlea (Ohyama et al., 2010). Moreover, Kölliker's organ expresses both Jag1 and Sox2 between E12 and E14 but, unlike vestibular sensory patches, does not go on to generate either hair cells or supporting cells. This suggests that Jagl signaling likely has a different role in the mouse cochlea versus the vestibular organs and all sensory organs of birds.

A second reason for the difference between the present study and the recent work of Pan and colleagues (2010) may be in the developmental stage at which Notch is activated. Pan et al. (2010) activated Notch signaling in the mouse otocyst between E9.5 and E11.5 and generated patches of sensory tissue-including hair cells - in nonsensory regions of the ear, including the cochlea. It is possible that competence of otic tissue to respond to Notch activation in this manner is lost with time, and our data indeed suggest that the nonsensory regions of the cochlea have lost competence to generate sensory tissue in response to Notch signaling by E13.5 (Fig. 7). Moreover it is not yet clear whether the hair cells generated by Pan et al. (2010) were of auditory or vestibular character. As discussed above, it is possible that canonical Notch signaling is sufficient to generate vestibular sensory tissue but is not sufficient to generate the more derived prosensory precursors of the organ of Corti.

\section{Consequences of losing RBPJ $\kappa$ repression in the ear}

Deletion of RBРјк causes a failure of canonical Notch signaling and null mutants for RВРјк display phenotypes similar to other Notch loss-of-function mutants (Honjo, 1996) such as Notch1 (Conlon et al., 1995), Pofut1 (Shi and Stanley, 2003), and double mutants of Presenilin1 and 2 (Donoviel et al., 1999). However, although RBPj $\kappa$ acts as a mediator of Notch target gene activation in the presence of canonical Notch signaling, it also acts a transcriptional repressor in the absence of Notch signaling (Tanigaki and Honjo, 2010). RBPjк mutants may therefore express some genes normally repressed by RBPj $\kappa$ in addition to exhibiting a loss of canonical Notch signaling. This can lead to defects in terminally differentiated cells where Notch signaling would normally be absent, such as those seen in neuronal progeny of sensory organ precursors in Drosophila Su(H) mutants (Koelzer and Klein, 2003).

The loss of $\mathrm{RBPj} \kappa$ repression may be an explanation for the cochlear hair cell death observed in RBРјк mutants (Fig. 5). In the absence of RBPj $\kappa$, hair cells and supporting cells differentiate in the developing organ of Corti (Fig. 5) in the normal basal-apical sequence. As discussed above, this represents clear evidence that canonical Notch signaling is not necessary for the formation of the prosensory population that gives rise to these cell types. A recent study in which $\mathrm{RBPj \kappa}$ was deleted with a different Cre driver reports the absence of hair cells in the late embryonic mutant cochlea with the exception of the apex (Yamamoto et al., 2011). This study suggested that hair cells do not differentiate in the basal regions of the cochlea. However, our data suggest that hair cells do differentiate in the normal basal-apical gradient but subsequently die. Previous studies in which Notch receptor cleavage is blocked with gamma-secretase inhibitors do not show significant cell death in the cochlea (Takebayashi et al., 2007; Hayashi et al., 2008; Doetzlhofer et al., 2009). We suggest instead that the de-repression of genes normally inhibited by RВРјк in cochlear hair cells may lead to their death in our RВРjк mutants.

\section{Canonical versus noncanonical Notch signaling in the inner ear}

Our data suggest that canonical Notch signaling is not necessary for the induction of the cochlear prosensory domain but is deployed later as the prosensory domain differentiates into hair cells and supporting cells. If canonical Notch signaling is neither necessary nor sufficient to induce the prosensory domain of the cochlea, is a noncanonical pathway responsible? Notch signaling is used at least twice to specify cell fates in the developing Drosophila eye. A first phase establishes a region of atonal-expressing progenitor cells and a second phase singles out a single atonalexpressing R8 progenitor cell through lateral inhibition (Ligoxygakis et al., 1998; Li and Baker, 2001). Current evidence suggests that the first phase of Notch signaling, termed "proneural enhancement," does indeed occur through a noncanonical, Suppressor of Hairless-independent pathway (Li and Baker, 2001). At present, the mechanism of this noncanonical Notch pathway in Drosophila is unclear. One possible noncanonical Notch pathway may involve the Deltex RING finger ubiquitin ligase (Matsuno et al., 1997; Ramain et al., 2001; Hori et al., 2004; Fuwa et al., 2006), although there is currently no clear evidence suggesting that Deltex is necessary for noncanonical Notch signaling. A second noncanonical Notch signaling pathway involving the Abl tyrosine kinase has been implicated in axonal pathfinding (Crowner et al., 2003; Le Gall et al., 2008). Finally, the mTOR pathway is able to regulate some aspects of Notch-dependent differentiation or Notch-responsive genes (Kelly et al., 2007; Endo et al., 2009), although current studies differ as to whether $\mathrm{mTOR}$ is regulated through a canonical or noncanonical Notch pathway (Chan et al., 2007; Perumalsamy et al., 2009).

We currently have no evidence for a RBPj $\kappa$-independent, Jag1-independent Notch signaling pathway in the cochlea. However, recent evidence from our group suggests that BMP signaling is necessary for the induction of the prosensory domain of the cochlea (Ohyama et al., 2010). In this study, ear-specific compound mutants of BMPR1 receptors Alk3 and Alk6 contain a cochlear duct that lacks a prosensory domain and instead differentiates exclusively into Kölliker's organ. It is therefore possible that the highly derived mammalian cochlea has co-opted an alternative, Notch-independent signaling pathway to specify the prosensory domain.

\section{References}

Bok J, Chang W, Wu DK (2007) Patterning and morphogenesis of the vertebrate inner ear. Int J Dev Biol 51:521-533.

Brooker R, Hozumi K, Lewis J (2006) Notch ligands with contrasting functions: Jagged 1 and Deltal in the mouse inner ear. Development 133: 1277-1286.

Cantos R, Cole LK, Acampora D, Simeone A, Wu DK (2000) Patterning of the mammalian cochlea. Proc Natl Acad Sci U S A 97:11707-11713.

Chan SM, Weng AP, Tibshirani R, Aster JC, Utz PJ (2007) Notch signals positively regulate activity of the mTOR pathway in T-cell acute lymphoblastic leukemia. Blood 110:278-286.

Chen P, Segil N (1999) p27(Kip1) links cell proliferation to morphogenesis in the developing organ of Corti. Development 126:1581-1590.

Chen P, Johnson JE, Zoghbi HY, Segil N (2002) The role of Math1 in inner ear development: uncoupling the establishment of the sensory primordium from hair cell fate determination. Development 129: 2495-2505.

Cheng HT, Kim M, Valerius MT, Surendran K, Schuster-Gossler K, Gossler A, McMahon AP, Kopan R (2007) Notch2, but not Notch1, is required for proximal fate acquisition in the mammalian nephron. Development 134:801-811.

Conlon RA, Reaume AG, Rossant J (1995) Notch1 is required for the coordinated segmentation of somites. Development 121:1533-1545. 
Crowner D, Le Gall M, Gates MA, Giniger E (2003) Notch steers Drosophila $\mathrm{ISNb}$ motor axons by regulating the Abl signaling pathway. Curr Biol 13:967-972.

Dabdoub A, Puligilla C, Jones JM, Fritzsch B, Cheah KS, Pevny LH, Kelley MW (2008) Sox2 signaling in prosensory domain specification and subsequent hair cell differentiation in the developing cochlea. Proc Natl Acad Sci U S A 105:18396-18401.

Daudet N, Lewis J (2005) Two contrasting roles for Notch activity in chick inner ear development: specification of prosensory patches and lateral inhibition of hair-cell differentiation. Development 132:541551.

Daudet N, Ariza-McNaughton L, Lewis J (2007) Notch signaling is needed to maintain, but not to initiate, the formation of prosensory patches in the chick inner ear. Development 134:2369-2378.

Doetzlhofer A, Basch ML, Ohyama T, Gessler M, Groves AK, Segil N (2009) Hey2 regulation by FGF provides a Notch-independent mechanism for maintaining pillar cell fate in the organ of Corti. Dev Cell 16:58-69.

Donoviel DB, Hadjantonakis AK, Ikeda M, Zheng H, Hyslop PS, Bernstein A (1999) Mice lacking both presenilin genes exhibit early embryonic patterning defects. Genes Dev 13:2801-2810.

Eddison M, Le Roux I, Lewis J (2000) Notch signaling in the development of the inner ear: lessons from Drosophila. Proc Natl Acad Sci U S A 97: 11692-11699.

Endo M, Antonyak MA, Cerione RA (2009) Cdc42-mTOR signaling pathway controls Hes5 and Pax6 expression in retinoic acid-dependent neural differentiation. J Biol Chem 284:5107-5118.

Fuwa TJ, Hori K, Sasamura T, Higgs J, Baron M, Matsuno K (2006) The first deltex null mutant indicates tissue-specific deltex-dependent Notch signaling in Drosophila. Mol Genet Genomics 275:251-263.

Han H, Tanigaki K, Yamamoto N, Kuroda K, Yoshimoto M, Nakahata T, Ikuta K, Honjo T (2002) Inducible gene knockout of transcription factor recombination signal binding protein-J reveals its essential role in $\mathrm{T}$ versus B lineage decision. Int Immunol 14:637-645.

Hartman BH, Reh TA, Bermingham-McDonogh O (2010) Notch signaling specifies prosensory domains via lateral induction in the developing mammalian inner ear. Proc Natl Acad Sci U S A 107:15792-15797.

Hayashi S, McMahon AP (2002) Efficient recombination in diverse tissues by a tamoxifen-inducible form of Cre: a tool for temporally regulated gene activation/inactivation in the mouse. Dev Biol 244:305-318.

Hayashi T, Kokubo H, Hartman BH, Ray CA, Reh TA, BerminghamMcDonogh O (2008) Hesr1 and Hesr2 may act as early effectors of Notch signaling in the developing cochlea. Dev Biol 316:87-99.

Henrique D, Adam J, Myat A, Chitnis A, Lewis J, Ish-Horowicz D (1995) Expression of a Delta homologue in prospective neurons in the chick. Nature 375:787-790.

Honjo T (1996) The shortest path from the surface to the nucleus: RBP-J kappa/Su(H) transcription factor. Genes Cells 1:1-9.

Hori K, Fostier M, Ito M, Fuwa TJ, Go MJ, Okano H, Baron M, Matsuno K (2004) Drosophila deltex mediates suppressor of Hairless-independent and late-endosomal activation of Notch signaling. Development 131: $5527-5537$

Jayasena CS, Ohyama T, Segil N, Groves AK (2008) Notch signaling augments the canonical Wnt pathway to specify the size of the otic placode. Development 135:2251-2261.

Kelley MW (2006) Regulation of cell fate in the sensory epithelia of the inner ear. Nat Rev Neurosci 7:837-849.

Kelly AP, Finlay DK, Hinton HJ, Clarke RG, Fiorini E, Radtke F, Cantrell DA (2007) Notch-induced T cell development requires phosphoinositidedependent kinase 1. EMBO J 26:3441-3450.

Kiernan AE (2006) The paintfill method as a tool for analyzing the threedimensional structure of the inner ear. Brain Res 1091:270-276.

Kiernan AE, Cordes R, Kopan R, Gossler A, Gridley T (2005a) The Notch ligands DLL1 and JAG2 act synergistically to regulate hair cell development in the mammalian inner ear. Development 132:4353-4362.

Kiernan AE, Pelling AL, Leung KK, Tang AS, Bell DM, Tease C, Lovell-Badge $\mathrm{R}$, Steel KP, Cheah KS (2005b) Sox2 is required for sensory organ development in the mammalian inner ear. Nature 434:1031-1035.

Kiernan AE, Xu J, Gridley T (2006) The Notch ligand JAG1 is required for sensory progenitor development in the mammalian inner ear. PLoS Genet 2:e4.
Koelzer S, Klein T (2003) A Notch-independent fucntion of Suppressor of Hairless during the development of the bristle sensory organ precursor cell of Drosophila. Development 130:1973-1988.

Lanford PJ, Lan Y, Jiang R, Lindsell C, Weinmaster G, Gridley T, Kelley MW (1999) Notch signalling pathway mediates hair cell development in mammalian cochlea. Nat Genet 21:289-292.

Lee YS, Liu F, Segil N (2006) A morphogenetic wave of p27Kip1 transcription directs cell cycle exit during organ of Corti development. Development 133:2817-2826.

Le Gall M, De Mattei C, Giniger E (2008) Molecular separation of two signaling pathways for the receptor, Notch. Dev Biol 313:556-567.

Li S, Mark S, Radde-Gallwitz K, Schlisner R, Chin MT, Chen P (2008) Hey2 functions in parallel with Hes1 and Hes5 for mammalian auditory sensory organ development. BCM Dev Biol 8:20.

Li Y, Baker NE (2001) Proneural enhancement by Notch overcomes Suppressor-of-Hairless repressor function in the developing Drosophila eye. Curr Biol 11:330-338.

Ligoxygakis P, Yu SY, Delidakis C, Baker NE (1998) A subset of notch functions during Drosophila eye development require $\mathrm{Su}(\mathrm{H})$ and the $\mathrm{E}(\mathrm{spl})$ gene complex. Development 125:2893-2900.

Livak KJ, Schmittgen TD (2001) Analysis of relative gene expression data using real time quantitative PCR and the 2(-Delta Delta C(T)) method. Methods 25:402-408.

Matsuno K, Go MJ, Sun X, Eastman DS, Artavanis-Tsakonas S (1997) Suppressor of Hairless-independent events in Notch signaling imply novel pathway elements. Development 124:4265-4273.

Morimoto M, Liu Z, Cheng HT, Winters N, Bader D, Kopan R (2010) Canonical Notch signaling in the developing lung is required for determination of arterial smooth muscle cells and selection of Clara versus ciliated cell fate. J Cell Sci 123:213-224.

Morrison A, Hodgetts C, Gossler A, Hrabé de Angelis M, Lewis J (1999) Expression of Delta1 and Serrate1 (Jagged1) in the mouse inner ear. Mech Dev 84:169-172.

Morsli H, Choo D, Ryan A, Johnson R, Wu DK (1998) Development of the mouse inner ear and origin of its sensory organs. J Neurosci 18: $3327-3335$

Murata J, Tokunaga A, Okano H, Kubo T (2006) Mapping of Notch activation during cochlear development in mice: Implications for determination of prosensory domain and cell fate diversification. J Comp Neurol 497:502-518.

Murtaugh LC, Stanger BZ, Kwan KM, Melton DA (2003) Notch signaling controls multiple steps of pancreatic differentiation. Proc Natl Acad Sci U S A 100:14920-14925.

Neves J, Parada C, Chamizo M, Giráldez F (2011) Jagged1 regulates the restriction of Sox2 expression in the developing chicken inner ear: a mechanism for sensory organ specification. Development 138:735744

Ohyama T, Groves AK (2004) Generation of Pax2-Cre mice by modification of a Pax2 bacterial artificial chromosome. Genesis 38:195-199.

Ohyama T, Basch ML, Mishina Y, Lyons KM, Segil N, Groves AK (2010) BMP signaling is necessary for patterning the sensory and non-sensory regions of the developing mammalian cochlea. J Neurosci 30:15044-15051

Okajima T, Irvine KD (2002) Regulation of notch signaling by o-linked fucose. Cell 111:893-904.

Okamura Y, Saga Y (2008) Pofut1 is required for the proper localization of the Notch receptor during mouse development. Mech Dev 125:663-673

Pan W, Jin Y, Stanger B, Kiernan AE (2010) Notch signaling is required for the generation of hair cells and supporting cells in the mammalian inner ear. Proc Natl Acad Sci U S A 107:15798-15803.

Perumalsamy LR, Nagala M, Banerjee P, Sarin A (2009) A hierarchical cascade activated by non-canonical Notch signaling and the mTOR-Rictor complex regulates neglect-induced death in mammalian cells. Cell Death Differ 16:79-89.

Ramain P, Khechumian K, Seugnet L, Arbogast N, Ackermann C, Heitzler P (2001) Novel Notch alleles reveal a Deltex-dependent pathway repressing neural fate. Curr Biol 11:1729-1738.

Sasamura T, Sasaki N, Miyashita F, Nakao S, Ishikawa HO, Ito M, Kitagawa M, Harigaya K, Spana E, Bilder D, Perrimon N, Matsuno K (2003) neurotic, a novel maternal neurogenic gene, encodes an $O$-fucosyltransferase that is essential for Notch-Delta interactions. Development 130:47854795. 
Schuster-Gossler K, Harris B, Johnson KR, Serth J, Gossler A (2009) Notch signalling in the paraxial mesoderm is most sensitive to reduced Pofut1 levels during early mouse development. BMC Dev Biol 9:6.

Shi S, Stanley P (2003) Protein $O$-fucosyltransferase 1 is an essential component of Notch signaling pathways. Proc Natl Acad Sci U S A 100: $5234-5239$.

Shi S, Stahl M, Lu L, Stanley P (2005) Canonical Notch signaling is dispensable for early cell fate specifications in mammals. Mol Cell Biol 25:9503-9508.

Srinivas S, Watanabe T, Lin CS, William CM, Tanabe Y, Jessell TM, Costantini F (2001) Cre reporter strains produced by targeted insertion of EYFP and ECFP into the ROSA26 locus. BMC Dev Biol 1:4.

Stern CD (1998) Detection of multiple gene products simultaneously by in situ hybridization and immunohistochemistry in whole mounts of avian embryos. Curr Top Dev Biol 36:223-243.
Takebayashi S, Yamamoto N, Yabe D, Fukuda H, Kojima K, Ito J, Honjo T (2007) Multiple roles of Notch signaling in cochlear development. Dev Biol 307:165-178.

Tanigaki K, Honjo T (2010) Two opposing roles of RBP-J in Notch signaling. Curr Top Dev Biol 92:231-252.

Wu DK, Oh SH (1996) Sensory organ generation in the chick inner ear. J Neurosci 16:6454-6462.

Yamamoto N, Chang W, Kelley MW (2011) Rbpj regulates development of prosensory cells in the mammalian inner ear. Dev Biol 353:367-379.

Zine A, de Ribaupierre F (2002) Notch/Notch ligands and Math1 expression patterns in the organ of Corti of wild-type and Hes1 and Hes5 mutant mice. Hear Res 170:22-31.

Zine A, Van De Water TR, de Ribaupierre F (2000) Notch signaling regulates the pattern of auditory hair cell differentiation in mammals. Development 127:3373-3383. 